\title{
Review of Web Mapping: Eras, Trends and Directions
}

\author{
Bert Veenendaal ${ }^{1, *}$, Maria Antonia Brovelli ${ }^{2}$ (iD) and Songnian $\mathrm{Li}^{3}$ \\ 1 Department of Spatial Sciences, Curtin University, GPO Box U1987, Perth 6845, Australia \\ 2 Department of Civil and Environmental Engineering (DICA), Politecnico di Milano, \\ P.zza Leonardo da Vinci 32, 20133 Milan, Italy; maria.brovelli@polimi.it \\ 3 Department of Civil Engineering, Ryerson University, 350 Victoria Street, Toronto, ON M5B 2K3, Canada; \\ snli@ryerson.ca \\ * Correspondence: b.veenendaal@curtin.edu.au; Tel.: +618-9266-7701
}

Received: 28 July 2017; Accepted: 16 October 2017; Published: 21 October 2017

\begin{abstract}
Web mapping and the use of geospatial information online have evolved rapidly over the past few decades. Almost everyone in the world uses mapping information, whether or not one realizes it. Almost every mobile phone now has location services and every event and object on the earth has a location. The use of this geospatial location data has expanded rapidly, thanks to the development of the Internet. Huge volumes of geospatial data are available and daily being captured online, and are used in web applications and maps for viewing, analysis, modeling and simulation. This paper reviews the developments of web mapping from the first static online map images to the current highly interactive, multi-sourced web mapping services that have been increasingly moved to cloud computing platforms. The whole environment of web mapping captures the integration and interaction between three components found online, namely, geospatial information, people and functionality. In this paper, the trends and interactions among these components are identified and reviewed in relation to the technology developments. The review then concludes by exploring some of the opportunities and directions.
\end{abstract}

Keywords: web mapping; Web GIS; Internet; online; web services; digital earth; GeoWeb; semantic web; collaborative; development era

\section{Introduction}

The United States Vice-President Al Gore's 1998 speech on digital earth technologies created an increased awareness of the value of geospatial information and its necessity to be available online and accessible to many users globally. Gore's vision was to harness technology and people to generate an immersive visual experience of travelling through virtual geographic space and time to understand our earth [1]. He identified the focus on applications such as conducting virtual diplomacy, fighting crime, preserving biodiversity, predicting climate change and increasing agricultural productivity. Interestingly, the two decades following that have seen huge developments of technologies and collaborative environments that bring people and information together, including digital globes, high speed communication networks, mobile wireless environments, location-based services, cloud computing and Web GIS. However, we still encounter many challenges and barriers including linking information around geographic location, analyzing and handling big geospatial data, discovering and interpreting intelligent information, immersive understanding of our digital Earth, harnessing crowdsourcing opportunities and communicating information to the global public in a manner that is contextualized and understood [2,3].

Since the beginning of the web and the first World Wide Web conference in 1994, the interactions among and between information and people have evolved dramatically. The web now is not simply a developing technology for content, but involves people who generate content, communicate and 
interact in collaborative environments [4]. New user needs evolve which are accommodated in further technology developments, which in turn lead to wider usage and additional user needs creating an iterative cycle of technology development and user/application growth and expansion.

Moreover, from the technological point of view the methods and tools for making maps available on the web have changed dramatically. The early origins of web mapping applications were "simply" tools allowing agencies and individuals to publish maps with user choices limited to browsing, zooming, panning, and turning on/off layers. The users were supposed to be active readers of the data but passive with respect to the possibilities of uploading pieces of information to the map itself and performing often-needed spatial analyses. Today, web mapping applications are introducing a broader range of functionality, including what traditional desktop GIS has provided but expanding beyond that to incorporate growing application requirements, with the advantage of being able to share content and analyze map data on the web.

In this paper, we want to outline the evolution of web mapping taking into account the perspectives of the designers/developers (experts/scientists) and of the users (novice and occasional users). The remainder of this paper is organized as follows. In Section 2, we provide a brief discussion about web mapping in general, i.e., its definition, main characteristics, and how to identify the web mapping eras. In the two sections that come after, we then discuss the trend of the web mapping, considering the following eras: static, dynamic, services, interactive, collaborative, digital globe, mobile, cloud and intelligent (Section 3) and the directions in the web mapping eras (Section 4). In Section 5, we summarize the paper with some concluding remarks.

\section{Background and Developments}

Web mapping has a relatively short but fast-paced history, with an impressive evolution related to both the dynamics of science and technology, and the increased interests of domain experts and global citizens in consuming new kinds of maps created by web mapping services.

The following sections introduce the concept of web mapping, discussing different available definitions, and its characterizations, which will then helping us in identifying the developments and significant events categorized into different development eras.

\subsection{What Is Web Mapping?}

Before introducing web mapping, we can identify some of the currently available definitions:

"Web mapping is ... : (1) information and data updating, (2) security and authentication of the user, (3) collection of user-filled forms (surveys, opinion polls etc.) and (4) access to databases." [5];

"Web mapping is the process of designing, implementing, generating and delivering maps on the World Wide Web." [6];

"Web mapping is the technique of utilizing maps that are obtained by an information system for spatial and geographical data." [7]; and

"Web mapping is the process of using maps delivered by geographical information systems (GIS)." [8].

Apart from the acknowledged scientific and technical definitions, we decided to also consider what is provided by Wikipedia for two reasons: it is a user-contributed definition which can be improved and enriched by everybody and it is one of the main sources of information for many people, sometimes scholars included.

We will see that, in fact, these definitions are reductive and, to have an exhaustive definition, the term web mapping needs to be put into context with the specific period it refers to.

Three basic elements are implied in web mapping: geodata/geoinformation and their visualization (maps), geospatial software and the World Wide Web, or the Web (web hereafter). Depending on the emphasis put on maps or on the technology and the processing of geodata to produce maps, people tend to consider the concept of web mapping as different from that of Web GIS (even if they admit that the boundary is blurry) or, on the other hand, they use the two terms 
as synonyms. For the sake of clarity, we chose to define Web GIS as a fully-fledged GIS that takes advantage of web technology for communicating among its components (data, functionality, and interface). The concept of web mapping is more general and focuses on providing and supporting mapping functions at different levels of complexity, for applications and users.

There are more terms, which are sometimes confused with web mapping and Web GIS. These include Internet GIS, GeoWeb (or Geospatial Web) and Distributed GIS.

Internet GIS [9] is a term often used synonymously with Web GIS. It is an Internet geospatial application that can use more services than only the web. Therefore, it is broader with respect to the applied technology but not as pervasive in usage as the term Web GIS. In reality, the web is the most commonly used Internet technology and Web GIS is the most common form of online GIS [10]. Hence we will use the term Web GIS to represent all online GIS.

For GeoWeb, one can find two different definitions: the former is about the merging of geospatial information with non-geospatial ones (photos, videos, news, etc.) [11]; the latter is as synonym of Distributed GIS, i.e., a widespread geospatial environment allowing the sharing of interoperable components.

Even if people have been using the same name, web mapping, the concept and practice of web mapping has dramatically changed over time, following the evolution of the interaction among the mapping data/information, the Internet, the web, the available tools and the citizens/users' attitudes [12]. If we want to summarize, we can say that web mapping consists of a website with mapping capability. The capability has grown in time and the interest of people in consuming (and more recently in contributing to) those websites has grown accordingly.

If we add the names of the eras, as they are proposed in this paper, we are better able to identify the characteristics of the specific type of web mapping we are referring to. For example, the beginning of web mapping was the equivalent of publishing static maps on the Internet, hence "static web mapping". With "intelligent web mapping", we mean the last frontier of web mapping, where context plays the fundamental role in the interaction between mapping/geographic information and users. Following on from the nomenclature proposed for the eras by other authors, we are better able to resolve most of the ambiguity surrounding the general term "web mapping".

\subsection{Characterization of Web Mapping Developments}

In the previous section, we defined web mapping through analyzing some existing definitions. In this section, we will move further to explore the characteristics of web mapping which can help: (1) distinguish web mapping from others, e.g., Web GIS, Internet GIS, etc.; (2) support the design of web mapping applications; and (3) inform the selection of web mapping technologies for developments.

Web mapping uses the web, the world's largest multimedia platform, to deliver maps and deals primarily with technological issues, but also requires additional studies on cartographic theories, among other issues. This means that web mapping not only follows various Internet protocols but also utilizes web specific protocols. It also means that new technologies and cartographic principles are needed to effectively design maps for web mapping delivery.

Different from desktop mapping technologies, web mapping is mostly not an off-the-shelf solution, although many of its core technologies have already been well developed. It often requires some programming and demands breadth in terms of skills, knowledge and organizational structures to deploy practical applications [13].

Web maps and their related content presented in a web environment, i.e., web browsers, require an appropriate interface and often optional functionality for queries and reports. When designing web maps, audience, interface (e.g., size, space and color) and fast-response functions become important factors to consider. For example, the interactive characteristic of web mapping requires that some operations, if not all, be carried out quasi-instantaneously to maintain relevance, logic flow and user's attention. Map layouts may be restricted by the limited space within web browsers and on 
the display of mobile devices. Further, new cartographic design rules are needed for web mapping applications [14], although much has already been explored in depth.

With the recent development of content-based and user-generated web mapping, Batty et al. [15] present six ideas (i.e., characteristics) of web mapping and neo-geography: (1) individual production and user-generated content; (2) application of the power of the crowd; (3) massive data produced; (4) principle of participation; (5) the effect of network; and (6) openness.

A number of attempts have been made to capture web mapping developments. This is mostly done concerning technology improvements at either a broad generic level or specifically linking to prominent technology initiatives. However, the above general characteristics of web mapping have become quite clear.

\subsection{Requirements for Defining Web Mapping Eras}

Figure 1 illustrates a brief history of major web mapping events along a timeline. The development of web mapping started right after the web was created, primarily in the form of published online maps, with the PARC Map Viewer being the first web-based map [16,17]. Relatively, web mapping has come a short way since its beginning but has achieved the level that may not be imagined two decades ago, attributing mainly to the advances in web technologies. What follows in this section is a brief description of various attempts by authors to describe web mapping events and developments as generations or eras, as adapted from and further detailed by Veenendaal [18].

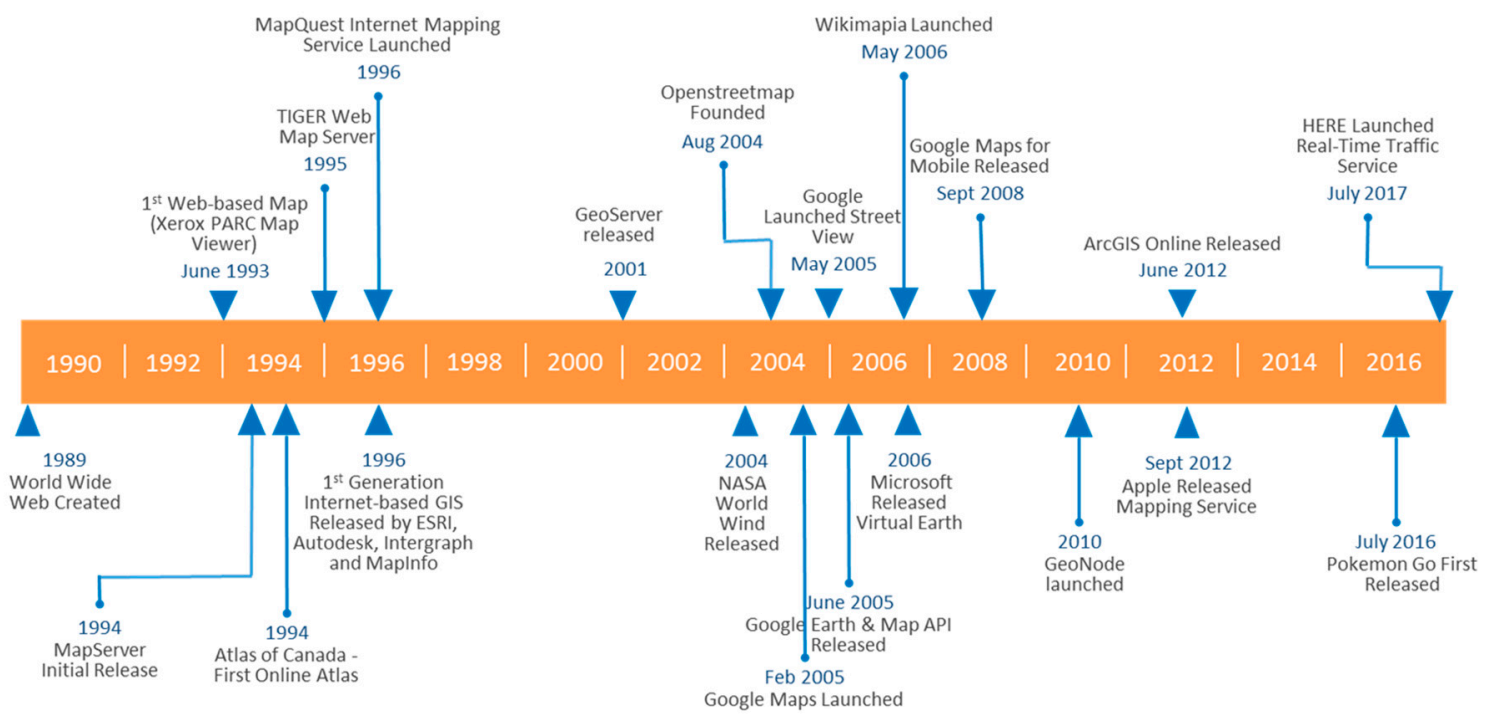

Figure 1. Timeline of some significant web mapping events.

In terms of its development, the web has generally been identified by various authors using four generations termed Web 1.0 to Web 4.0 (and beyond) $[19,20]$. Web 1.0, as the Hypertext Web, defined the first era of read webs, focused on retrieving information. The basic HTTP and HTML technologies were the primary means to disseminate online linked information according to the vision of Berners-Lee [20]. Web 2.0, referred to as the Social Web, is a read-write web where users can interact collaboratively for content creation, modification and sharing [21]. Web 3.0 is also known as the Semantic Web and focuses on enabling machine understanding of semantically structured data that provide users with more meaning and relevant information [22,23]. Choudbury [19] describes Web 4.0 as the ultra-intelligent agent that makes decisions as powerful as the brain to enable collaboration among communities. Although there are various attempts at describing Web 5.0, some naming it as the Sensory and Emotive Web [24,25], it remains essentially undefined and speculative. 
The generations of general web development have laid the foundation for web mapping development, which has come through a number of distinct yet interconnected or overlapping stages. Table 1 summarizes previous characterized eras by various authors with respect to different web generations, if applicable.

Table 1. Previously characterized eras of web mapping (Adapted from [18]).

\begin{tabular}{|c|c|c|c|c|}
\hline Peng \& Tsou, 2003 & Tsou, 2005 & Plewe, 2007; Tsou, 2011 & $\begin{array}{c}\text { Hall \& Tiropanis, } \\
2012\end{array}$ & $\begin{array}{l}\text { Multiple Authors } \\
\text { over Various Years }\end{array}$ \\
\hline $\begin{array}{ll}\text { - } & \text { Static } \\
\text { map publishing } \\
\text { - } & \text { Static } \\
\text { - } & \text { web mapping } \\
\text { Interactive } \\
\text { web mapping } \\
\text { - } & \text { Distributed } \\
\text { GIServices }\end{array}$ & $\begin{array}{l}\text { GIS awareness - } \\
\text { free satellite } \\
\text { imagery, } \\
\text { disaster response } \\
\text { User response } \\
\text { times - AJAX, } \\
\text { image tiling } \\
\text { - Virtual globes \& } \\
\text { online } \\
\text { mapping services }\end{array}$ & $\begin{array}{ll}\text { - } & \text { First generation } \\
\text { - } & \text { - static } \\
\text { - } & \text { - dynamic } \\
\text { - } & \text { Third generation } \\
\text { - interactive } \\
\text { - } & \text { Fourth generation - } \\
\text { virtual earth globes } \\
\text { - } & \text { Fifth generation - } \\
& \text { Cloud computing, } \\
\text { RIAs, crowdsourcing }\end{array}$ & $\begin{array}{ll}\text { - } & \text { Web } \\
\text { of documents } \\
\text { - } & \text { Web of people } \\
\text { - } & \text { Web of data \& } \\
& \text { social networks }\end{array}$ & $\begin{array}{ll}\text { - } & \text { Web } 1.0 \\
\text { - } & \text { Web } 2.0 \\
\text { - } & \text { Web } 3.0 \\
\text { - } & \text { Web } 4.0 \\
\text { - } & \text { Web 5.0? }\end{array}$ \\
\hline
\end{tabular}

Peng and Tsou [9] considered that early web mapping had gone through stages of static map publishing, static web mapping and interactive web mapping. Tsou [26] further approached the evolving world of web mapping by highlighting the major technology changes. Although only focusing on the year 2005, he identified three significant developments (see Table 1). Firstly, GIS awareness grew significantly among the general community fueled by the release of free satellite imagery on the one hand, and by occurrence of major disaster events on the other. Events in 2005 such as the South Asia Tsunami and Hurricane Katrina alerted the global community to the importance of using mapping and GIS technology to manage and respond to such events. A second significant development in 2005 highlighted by Tsou [26] was two new Internet technologies, namely AJAX and image tiling, both focused on increasing the response times of web maps for users. These technologies formed the foundation for the development of virtual globes and online mapping services, identified as the third major change by Tsou [26]. Included in this change were also the wireless location-based services resulting in mobile access to GIS and mapping technologies.

Plewe [27] identified four generations of web maps based on the types of technologies underpinning the map (see Table 1). The first generation maps were static maps such as those pioneered by the Xerox PARC map server [16]. They were static maps embedded in HTML files with simple click access via hyperlinks. The hyperlinks gave users some measure of choice in selecting the maps for viewing. The next generation comprised dynamic HTML maps created on-the-fly using Java and ActiveX with the map user interfaces starting to appear similar to GIS interfaces at that time. However, functionality was limited to map browsing and simple queries. The third generation web mapping was spurred on by the development of the Asynchronous JavaScript and XML (AJAX) technology, which improved response times and paved the way for direct user interaction with the map. This made way for open-service application programming interfaces (APIs), which could be accessed and combined with user contributed data in the generation of mashups.

Finally, the fourth generation was focused on virtual earth globes such as Nasa World Wind, Google Earth and Microsoft Bing, which provide users with a more realistic and immersive experience with a three dimensional Earth. The advent of these first public web services with global coverage of digital imagery opened up the geospatial world of mapping to the public community worldwide via the Internet. The ability to generate maps expanded well beyond the small group of web developers and mapping experts. As Plewe [27] points out, the result is that knowledge and interest in places of experience become the realm of the average citizen, no matter where in the world they are located. 
Following on from Plewe's [27] four generations of web mapping, Tsou [28] described a fifth generation built on cloud computing, rich Internet applications (RIA) and crowdsourcing. Rather than focusing on obtaining sufficient hardware resources and downloading desktop software, users can access cloud computing resources and services, which now include, for example, Amazon cloud storage and web services, Microsoft Azure cloud and ESRI ArcGIS Online. RIA refers to a web programming environment that provides a friendly user interface and access to powerful widgets and tools (e.g., Google Web Toolkit and Adobe FLEX).

In fact, the focus on web mapping developments goes even further than information and people. It goes to the heart of people interactions and engagements at a global level. Hall and Tiropanis [1] identify stages of web evolution based on the primary focus of the developments (see Table 1). The web first appeared as the web of documents, was then transformed into a web of people, and now is developed as the web of data and social networks. The latter transition of the web is focused on a stronger link involving people and data, namely the people-to-people interactions around information and knowledge, which includes community mapping, location-based and mobile activities, dynamic processes and interactions, etc., in geographic context.

\section{Web Mapping Eras of Development}

As discussed in the previous section, the development of web mapping has gone through a number of important stages over the past several decades. Particular developmental events and characteristics have had a significant influence on the use and further development of web mapping. In order to assist in characterizing these developments, we have identified a range of web mapping eras which highlight some of the most influential and significant events. We firstly define the criteria that are used to identify an era, and then explain some of the highlights that particularly mark each era.

\subsection{Criteria for Defining Web Mapping Eras}

An era can be defined as a "period of time marked by distinctive character, events, etc." [29]. In order to define web mapping eras, significant web mapping developments have been identified that have had a major influence on the global community. The eras previously identified in the literature (refer to Section 2.3) primarily focus on technology developments, apart from one that is related to user adoption, namely, GIS awareness [26]. However, these distinctive events need not be exclusively technological, as evidenced by the eras that Hall and Tiropanis [4] identified, namely, in relation to people and social networks (refer to Table 1). Hence, the focuses of the eras identified in this paper are on significant developments that may be driven by users as well as technology. In practice, these two drivers are closely aligned since the success of developments is determined by usage, which is the uptake of technology by users.

The one or more developments that make up an era may occur as an event at a particular point or period in time, or as a character that appears and becomes prominent over a particular time period. However, this does not mean that the development is constrained to only that range or point in time. An event or character may mark the beginning of the development, where continued expansion and progress are made in subsequent eras. Thus, the developments that make up an era are not to be seen as being exclusive to that era, but mark the beginning of a continuing development that extends into subsequent eras. Further, different eras may overlap in time because developments may have occurred simultaneously or within the same time period.

The continuing expansion or development of an event may lead to further events in subsequent eras. Often, particular web mapping events provide the foundation for and a gateway to further developments. In fact, if the development has a substantial influence, that influence will be felt and used to drive further developments. The building blocks of new events are often the combination of multiple events from previous eras. Hence, the web mapping eras will be defined with events or characterizations that influence new events or characterizations in subsequent eras.

In summary, the criteria for identifying web mapping eras are: 
1. Must be aligned with one or more developments distinguished by one or more particular characters or events and that have a significant influence on web mapping developments (technology, data) and communities;

2. Developments need not only be technology driven, but can also be user driven, or even a combination of new technological development resulting in increased users or usage;

3. Developments within a particular era need not be constrained to that era alone, but may continue to flow into, expand and have influence across subsequent eras;

4. The eras, and developments within them, may overlap in time; and

5. Developments identified in an era will influence newer developments in subsequent eras.

\subsection{Web Mapping Eras}

The definition of the web mapping eras identified in this paper builds on the past work that was introduced in Section 2.3 and those identified by Veenendaal [18]. The criteria identified in Section 3.1 were used to determine and distinguish the eras and their associated web mapping developments. Note that some eras comprise purely technological developments (e.g., Services era), others mostly user-based developments (e.g., Collaborative era) and others driven by both technology and users (e.g., Digital Globe era).

Nine web mapping eras were identified and placed in a timeline to mark significant developments. Figure 2 names and provides a summary of each era, a short list of the significant web mapping developments within that era, with a star indicating the approximate commencement of the developments in that era. No "end" of an era is defined as many of these developments have either continued or been embedded or expanded in subsequent eras. The key or influential developments within each era are explained in the following sections.

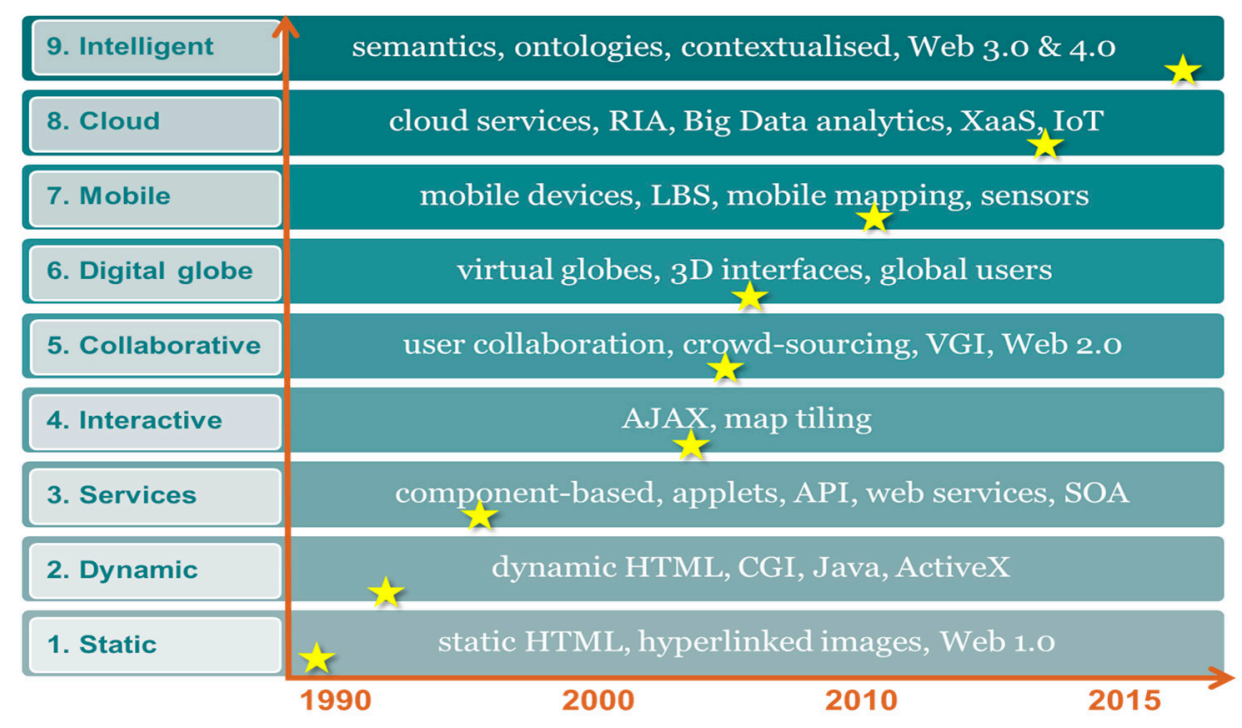

Figure 2. Framework of web mapping eras (Adapted from [18]).

\subsubsection{Static Web Mapping Era}

The static web mapping era refers to the beginnings of Web 1.0 in the early 1990s, where the phenomena of a web map was realized through an HTML image, especially clickable images, and hyperlinks [14]. This era is equivalent to Plewe's [27] first generation web maps. Web 1.0 defines the read-only web focusing on the retrieval of information from what was then essentially a data repository of web pages. This era was founded on the basic HTTP and HTML technologies implemented to disseminate online linked information according to the vision of Berners-Lee [20]. A client-server architecture was used where the client was a browser on a local computer through which the user 
interacted, and which communicated with a server, which was the remote computer that served the data as requested back to the client. HTTP was the protocol in which client and server functioned, and HTML was the language in which they communicated.

These basic developments were expanded with HTML Forms and Common Gateway Interface (CGI) to facilitate user input on the client side and processing ability on the server side [9]. Users could now be provided simple choices to select specified parameters regarding the content, options and layout of the map. Being able to store and retrieve a (traditional) map on the web was a major step in being able to share maps with multiple users beyond the paper-based map. A very well publicized example of a static web map was pioneered by Xerox [16,17] with its Xerox PARC map server in 1993. These maps were embedded in HTML files with simple click access via hyperlinks to predefined map parameters such as zooming in and out, projection changes, display layers, change database and preset coordinates [30]. In essence, the user could select which predefined static maps to view. These foundational technologies marked the start of the further developments of web mapping.

\subsubsection{Dynamic Web Mapping Era}

Once multiple users started to share web maps, the next logical progression was to be able to modify the map for a user or customize for different users. Dynamic maps created using Dynamic HTML (DHTML), Common Gateway Interface (CGI), Java applets and servlets, plugins and ActiveX technologies enabled users to retrieve maps that were dynamically created and constructed on the server according to user preferences and choices [9]. Users clicked on the map or on hyperlinked buttons around the map to identify their map selections, which were sent as user requests to the server where the map was dynamically constructed and sent back to the client. In fact, the two-tier client-server architecture evolved into a multiple or n-tier architecture where the presentation, application and database server functions are separated and able to be provided on different computers. Hence, the data could be requested from multiple database servers, assembled by server-side application (map server) and provided as a response to a user request, all from different computers on the Internet.

Dynamic maps provided a measure of interaction with maps, so that users could control and manipulate what they were viewing. This opened the way for interactive online atlases and the beginnings of GIS functionality on the web. For example, one of the first online atlases in the world was the Atlas of Canada launched in 1994 [31], which gave users the opportunity to select layers and submit the request to view the resulting map. The United States Geological Survey implemented the National Geospatial Data Clearinghouse in 1995 as a web portal that allowed users to search for maps, geospatial data and satellite images using keywords and map windows [32]. This dynamic web mapping technology opened the way to increasing user interaction through subsequent developments (refer to Section 3.2.4).

\subsubsection{Services Web Mapping Era}

The development of many maps generated by map servers and a range of mapping options for users to view maps online, came with the need to package and standardize the interface to these web map servers. The purpose is to provide mapping information directly, not just to users, but also to other software programs that can consume and produce information. In the services web mapping era, component-based technologies such as Java Applets, CORBA, Microsoft.NET, etc. were used to create replaceable components with well-defined interfaces to facilitate a flexible and interoperable environment [9]. These components are assembled as web services within a service-oriented architecture (SOA), which can be published, invoked and discovered on the web. A web service receives requests, provides the data manipulation and functionality to service the request, and responds via its defined interface. Web clients can interact with the service via programs and browsers directly or indirectly with users. 
This paved the way for open-service application programming interfaces (APIs) which could be accessed allowing user choices or even combined with user-contributed data in the generation of mashups. An API [33,34] provides a software-to-software interface beyond the user-to-software interface, thereby making the software accessible by a whole range of software applications. It makes it possible to combine layers from different services creating a commonly-defined and easily shareable "front end". API interfaces unlock online data servers and provide easier access to store, retrieve and link multiple online data repositories. They empower developers to customize and personalize web maps beyond those made available (and often limited) by vendor solutions.

APIs designed specifically for making web maps include Openlayers [35], Leaflet [36], D3 [37], Google Maps API [38], Microsoft's Bing Maps [39] and ArcGIS APIs such as the ArcGIS API for JavaScript [40], which is the richest and most fully-fledged among the ESRI family. Many APIs are currently based on JavaScript and HTML. Most of them provide connections to data services but there are also examples that allow interfaces to processing services, e.g., ArcGIS APIs, taking advantage of the functionalities of the ArcToolbox, or OpenGeoSuite [41].

An early example of a web mapping service involves the United States census data, represented as TIGER files, which was released via an online web map server in 1995; this also marks the approximate commencement of this era. Through this service, users could query and map the demographic data of the United States [42]. This service was subsequently retired in May 2010 and replaced by the TIGERweb, which incorporates web mapping and streaming services [43].

In 1996, MapQuest released an address matching and traffic routing web mapping service to find business locations, optimum routes to a location, and plan trips [44]. In fact, this was one of the first examples of where web services began to provide GIS functionality, in this case geocoding and routing functions.

Susan Huse developed GRASSLinks in 1995 for her PhD, which exposed GRASS desktop GIS tools to a web browser via a web server [45]. This provided the opportunity for users to access GIS functions directly from the web, paving the way for the development of Web GIS.

The European Union (EU) GeoPortal was developed for the discovery, evaluation and use of existing geospatial datasets [46]. It was designed to provide, beside catalogue services, gazetteer, thesaurus, feature, portrayal (e.g., cartographic representation) and some processing services (e.g., coordinate transformation and generalization).

An important contribution to web mapping services was the development of standards and specifications by the Open Geospatial Consortium (OGC). Some of the first standards issued by the OGC include Web Mapping Services (WMS) with the first version released in 2000 for web maps [47], Web Feature Services (WFS) in 2002 for vector-based features [48], Web Coverage Services (WCS) in 2005 for raster based data [49], and Web Processing Services (WPS) in 2007 for processing operations [50]. The number of geospatial standards has since increased to over 50 specifications currently released by the OGC to support web mapping and the GeoWeb.

\subsubsection{Interactive Web Mapping Era}

The limitation of the early dynamic maps was that client requests and server responses were synchronized so that users, after submitting a map request, had to wait patiently for the server to assemble and return the response. The technological solution to enhance user interaction with the map was to provide user-client interaction simultaneously with client-server interaction. The interactive web-mapping era equates with Tsou's [26] second significant development and Plewe's [27] third generation web maps and builds on dynamic web mapping technology. The emerging AJAX technology combined with image tiling technology significantly enhanced user interaction with the map by allowing online maps to be delivered to a user in a continuous and responsive manner while the user was simultaneously interacting with the map interface.

Asynchronous JavaScript and XML (AJAX) are a group of technologies including JavaScript and XML, which allow the client to simultaneously communicate with the server and the user [51]. 
The result is a faster response to the user, while the client continues to receive data simultaneously from the server. Google Maps and Google Suggest were early users of AJAX technology. While the downloading of image tiles occurs in the background in an asynchronous fashion, the user experiences no wait time while viewing a continuously refreshing and emerging image [26].

A second relevant advantage of the interaction was the possibility of geographic mashups of maps. Mashups are the dynamic and personalized combination of data from multiple sources combined into one map [52,53]. This technology now became achievable, thanks to AJAX, applets and the emerging web map development environments (Java, Flash, Silverlight or customized plugins) or heavier standalone geo-browsers. Consequently, mashups were utilizing the increasing number of available APIs, particularly for growing number of online datasets (including basemap imagery) via map servers, to facilitate improved access to geospatial data and maps by developers and end users.

\subsubsection{Collaborative Web Mapping Era}

The increased focus on the user experience that resulted from the interactive web mapping era, paved the way for this new era. The start of the Web 2.0 developments opened the way for more users to participate in both mapping retrieval and data creation activities. Web 2.0, a term coined by DiNucci [54], refers to the read-write web where user interaction is extended to, not only the choice of parameters for the selection and viewing of content, but also the creation of user-generated content [10]. O'Reilly [21] gave the first systematic and complete definition of Web 2.0, highlighting that, instead of simply disseminating information created by a webmaster, "the central principle behind the success of the giants born in the Web 1.0 era who have survived to lead the Web 2.0 era appears to be this, that they have embraced the power of the web to harness collective intelligence".

The emergence of Web 2.0 in the mapping domain can be dated to 2005, when both new web mapping applications and new communities behind those applications have appeared. It is worth noting that, in their "Web Squared" Report, O'Reilly and Battelle [55] mention many examples related, directly or indirectly, to web mapping. This gives a clear hint about the importance acquired to geospatial information in contextualizing collaborative user-generated content. In the previous years, in fact, big web mapping collaborative platforms were put in action both by private companies (such as Google Map Maker-now integrated into Google Maps—and Microsoft Bing Maps) and by communities (such as OpenStreetMap).

OpenStreetMap (openstreetmap.org) was founded in 2004 as one of the first widespread efforts to provide a mapping platform for volunteered data capture [56]. What started as a mapping exercise for the United Kingdom spread rapidly across the entire world. Geospatial data are redistributed under the ODbL license: users are free to share, create and adapt the database as long as they attribute, share-alike and keep open.

Another example of a collaborative mapping platform is Wikimapia launched in 2006 [57]. The goal was to build a participative map where people worldwide could describe the whole world. Data are released under CC-BY-SA license, even if, being mainly derived from Google Maps, there can be problems in reusing them in some countries, depending on the specific jurisdiction.

Some new terms, such as Crowdsourcing and Volunteered Geographic Information (VGI), were coined. VGI became integrated into many desktop and mobile apps so that the user communities are not only consumers of geospatial information and maps, but also producers that contribute to the shared knowledge of our world [58]. This fed into the generation of communities linking to and utilizing a host of related technologies including mashups, blogs, wikis, social networking and shared atlas/mapping portals.

\subsubsection{Digital Globe Web Mapping Era}

Arguably one of the most significant events, the Digital Globe (or sometimes named virtual globe or virtual earth) web mapping era has opened up the power of mapping to the global community. The advent of digital globes was identified by Tsou [26] as the third significant development in 2005 and 
by Plewe [27] as the fourth generation of web mapping. Digital globes have exploited the benefits of the emerging technologies (e.g., from Services, Interactive and Collaborative era developments) to generate an environment in which the user is provided with an immersive experience in Earth imagery, not only in 2D but also in a 3D (actually 2.5D) environment. The emergence of Google Earth, Microsoft Virtual Earth (now BING), Cesium, NASA World Wind and a host of additional virtual earth platforms, have exposed maps and digital earth imagery to the common everyday citizen and made possible real-time, synchronous sharing of views within a group of people joining a conference session. The digital globe interfaces, realistic earth imagery and public global data brought the world to the desktop, more recently to mobile devices and through web browsers, like no other previous mapping applications ever did.

The advent of these first public web services with global coverage of digital imagery opened up the geospatial world of mapping to the public community worldwide via the Internet. The ability to generate maps expanded well beyond the small group of web developers and mapping experts. As Plewe [27] points out, the result is that knowledge and interest in places of experience become the realm of the average citizen, no matter where in the world they are located. The user base suddenly expanded exponentially from the specialist community to the global community, essentially anyone who has an Internet connection, which is now ubiquitous in the world. The scientific benefits of using virtual globes due to their data presentation and visualization power are also asserted by many applications. Digital globes have become a tool for grassroots mobilization, environment protection and emergency/disaster response for many non-for-profit and public organizations.

While the number of ready-to-use or off-the-shelf virtual globes is increasing, new technologies that enable open and pervasive development of virtual globes and their applications are rapidly evolving. A number of open-source solutions, e.g., NASA World Wind, Cesium WebGL, Glob3 Mobile and osgEarth [59-61], have made the development of virtual globe applications easier. The virtual globe APIs, such as the Google Maps API first released in 2005, also enhanced access to published online imagery basemaps by developers who could incorporate shared imagery more easily into mashups and other web map interfaces. These developments strongly influenced the uptake and expansion of web mapping by a broader base of users.

Starting with a simple three-dimensional (3D) software model or representation of the Earth viewed through desktop installations or within web browsers, the virtual globe has moved from 3D mapping, modeling and simulation to more recent integration with virtual reality (VR), gaming and Citizen Science. An example is the recent Google Earth VR project that aims at providing people with VR experience over the Google Earth platform [62]. Another example is the platform for sharing user-generated content (Figure 3) built over Nasa World Wind [63]. The collaborative platform, named Policrowd, visualizes the points of interest (POI) and related multimedia files (texts, pictures, sounds, videos), collected and contributed by the citizens through apps. Moreover, everyone can upload new comments and multimedia content to enrich and share the information related to each POI. No doubt, this era of web mapping with virtual globes still has long way to go, for example, to be adopted for time-critical applications such as self-driving with augmented reality.

\subsubsection{Mobile and Location-Based Web Mapping Era}

The advent of mobile hand-held devices, including personal digital assistants (PDAs), tablets and smartphones [64], opened up the opportunities for users to access and interact with online maps irrespective of their place and time. Not only web access to maps, but particularly access to the geographic location of the device became crucial to the rapid development of location-based services (LBS) $[65,66]$. Tsou [26] identified the contribution of LBS to the provision of online GIS services as one of the significant developments in 2005. The use of cell phone tower triangulation techniques and GPS-enabled smartphones enabled the location of users to be identified, via their smartphones, and embedded in emerging location-aware mobile and desktop apps $[26,65,67]$. 


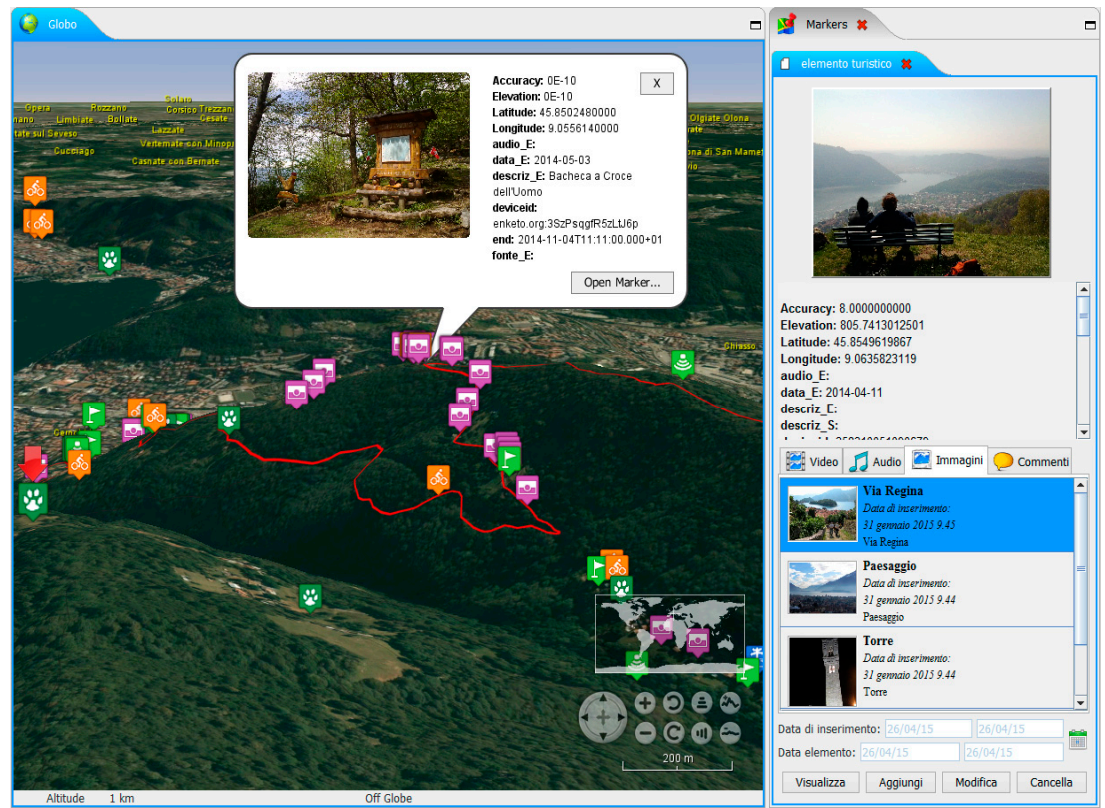

Figure 3. Virtual globe based on NASA World Wind for sharing and managing user generated content.

Access to a user's location in real-time paved the way for the development of a wide range of applications including marketing nearby retail and restaurant services, navigating from the current location to geocoded addresses, and playing location-based games. The applications for LBS include emergency services, marketing, navigation, traffic monitoring, weather monitoring, health, sports, tracking, etc. Not only can users retrieve information relative to their geographic location, but they can also participate in their environment by contributing information via apps (for example, see Prylutskyi [68]). This is related to a branch of the new Citizen Cyberscience called participatory sensing [69]. An example is the Via Regina app developed by Brovelli et al. [70] for tourist participatory sensing, where users can share locations, descriptions, photos and ranking of elements they are collecting while visiting and exploring tourist sites (Figure 4).

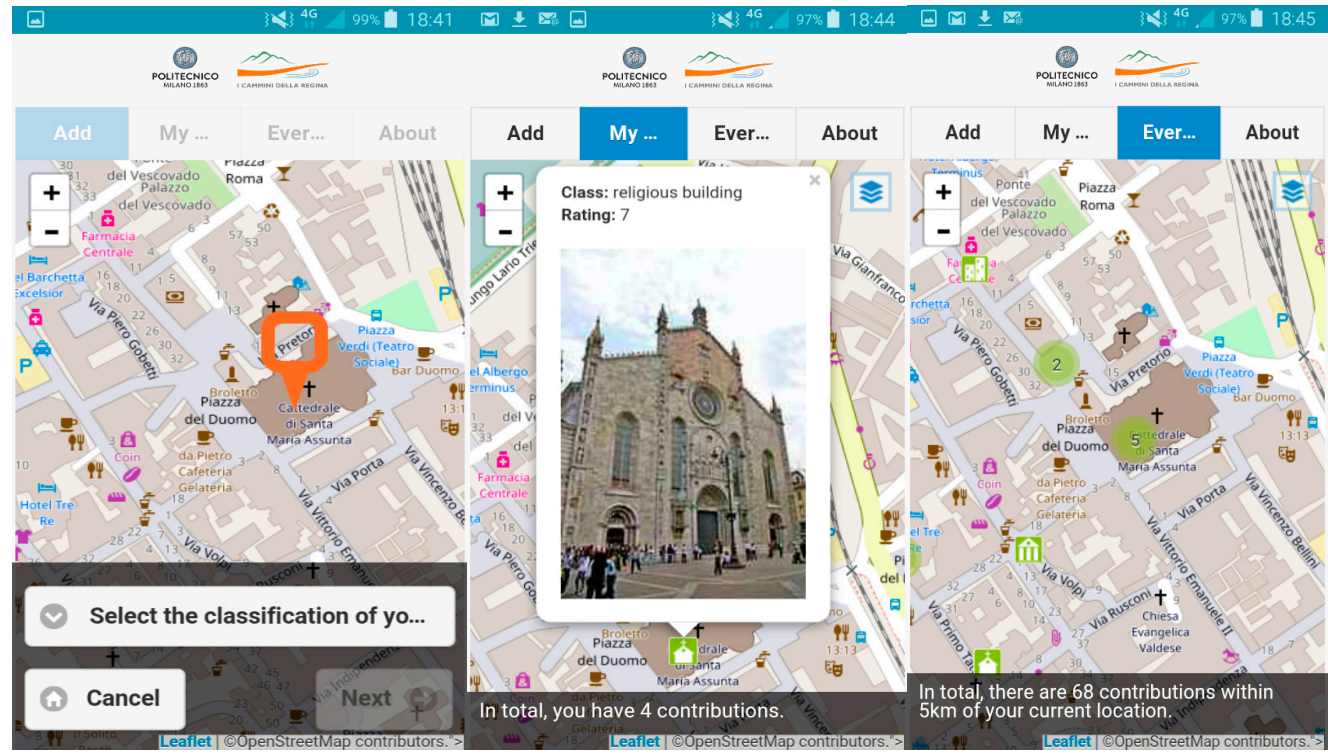

Figure 4. The Via Regina app: an example of participatory sensing. Users, after sensing, can view their own data (My Map) as well as that contributed by others (Everyone). 
Vehicle-mounted GPS and cellular-enabled navigation devices, either standalone or via smartphone apps, have transformed the transport industry by providing location-based routing information, live road conditions, re-routing suggestions based on empirical route modeling, and access to services and other information in proximity to current location. Health-based apps track personal daily movements or sports-based activities such as walking, running and cycling (e.g., RunKeeper, Strava). Location-based gaming includes such activities as geocaching, where players use their smartphone location to navigate to certain places to find and replace treasures [71], and Foursquare for users to discover places, find their friends and obtain points as they frequent certain venues and move about daily life [72].

In addition to location, apps are now also using augmented reality, which combines real and virtual reality by overlaying virtual objects and information on the real world as seen through the smartphone camera. Applications include discovering airplanes and ships in real-time, visualizing infrastructure that is hidden beneath the ground or behind walls, etc. Pokemon Go is an augmented reality game, recently released in July 2016, which encourages players to get out finding and interacting with their favorite Pokemon Go characters overlaid on the real world camera view [73].

A further development of location-based data capture relates to sensors that have location and sensor parameter data linked to the web. Mobile mapping refers to the capture of 2D and 3D data from a vehicle that is fitted with GPS and other sensing or imaging devices that may include photographic cameras, video, radar, radio, laser or LiDAR (Light Detection and Ranging) [74]. Sensor data may include environmental (e.g., temperature and rainfall), traffic monitoring, industrial process monitoring, health monitors (e.g., wearable sensors for elderly or emergency workers), webcam imagery and airborne sensor imagery [75]. Although many of these sensors may be fixed in location, many could also be mobile themselves, including trackers worn by animals and people, vehicle trackers and, of course, mobile phones. The OGC has developed the Sensor Web Enablement (SWE) standards to accommodate the communication of sensor location and parameters across the web in the growing market of applications.

\subsubsection{Cloud Web Mapping Era}

The cloud web mapping era focuses on the availability and scalability of increasing masses of information, with the cloud providing a solution. Now storage, software, services and infrastructure can be provided on the web in the cloud as services, providing a measure of reliability, stability and scalability for information, applications and users. This era was identified by Tsou [28] as part of a fifth generation of web mapping technology, following on from Plewe's [27] four generations. Cloud technology provides resource pooling, virtualized applications and a shared platform from which mapping applications and databases can be built, integrated and shared on the web.

Examples include for example, Amazon's cloud storage and web services, Microsoft Azure cloud, ESRI ArcGIS Online, GeoNode, GIS Cloud, and CartoDB. Cloud computing supports the expansion of the digital earth technologies as well as complex geospatial applications [76]. It encourages rich Internet applications (RIA) which refers to a web development environment that provides a friendly user interface and access to powerful widgets and tools. Examples include Google Web Toolkit and Adobe FLEX. The cloud also provides a platform to manage and manipulate big data, which is a characteristic of the growing volumes of geospatial data being collected through sensors and mobile devices [77]. Emerging platforms, such as the open source Hadoop [78], Hive [79], and MongoDB [80], provide distributed and parallel computing environments to perform geospatial big data analytics. The cloud computing is based on a service-oriented architecture, where "everything is a service". This concept is summarized in the acronym XaaS, which stands for Everything-as-a-Service and includes the cloud services models [81]:

- Software as a Service (SaaS) - users with a (thin) client via a web browser to use the provider's applications running on a cloud infrastructure. Example of SaaS is the GIS as a Service, characterized by management and integration of GIS workflows, in case with BI (Business 
Intelligence) integration. A second example can be that of Image as a Service provided by the ESA Sentinel Application Platform, SNAP [82].

- Platform as a Service (PaaS) - the users are provided with a full development platform where they can create, run, and host their own applications. A typical example is the Google App Engine that provides users the capability to develop their applications using Python, Java, PHP, etc.

- Infrastructure as a Service (IaaS) - where users are on demand offered by service providers compute resources, storage and networking capabilities. Such architectures include Amazon Web Services (AWS), Windows Azure, Google Compute Engine, Rackspace Open Cloud, and IBM SmartCloud Enterprise. For example, exploiting such an infrastructure (in the specific case Google Compute Engine), Descartes Labs is able to process huge amount of images from the NASA and other satellites to analyze variables such as the growth and health of crops, the growth of cities, the spread of forest fires and the state of available drinking water across the globe [83].

Cloud web mapping is obviously general purpose and relevant examples in many fields can be found. Mapstory [84], for example, is an infrastructure for "Map Story telling", enabling students, teachers or practitioners to convey their stories using maps and time as glue for their narration. Harvard WorldMap [85] is an online cloud-mapping platform developed for educational purposes. Masdap [86] is a public platform for GIS data to support development in Malawi.

A relevant aspect to be mentioned referring to the cloud web mapping is the Internet of Things (IoT): millions to billions of sensors directly or indirectly connected to the Internet [87]. IoT is going to generate an enormous amount of data and the cloud is currently the only way for efficiently storing, processing and analyzing these data [88]. Location, together with time, is one of the main keys to contextualize data and therefore a new subcategory within IoT is emerging, the "location of things" [89]. Some authors tend to give a more general interpretation to the phenomenon, speaking about Internet of Events (IoE), which is composed, at the same level of dignity, by IoT and Internet of Locations (IoL) [90]. Whichever could be the classification, the focal point is that location matters and the web mapping combined with the storage and analytics offered by the cloud, remains one of the most powerful tools for analyzing the data through interactive visualization.

\subsubsection{Intelligent Web Mapping Era}

The intelligent web mapping era embraces semantic technologies and smart environments that provide knowledge, context and customization to the information delivered to users and applications. Although still evolving and being defined, this era tries to encapsulate the fact that knowledge must be extracted from data and information and intelligently contextualized for users and applications. Both semantics and context must be represented, constructed, discovered and used in a way that intelligently filters appropriate information for better knowledge and decision-making.

Web 3.0, also referred to as the semantic web, focuses on enabling machine understanding of semantically structured data that provides users with more meaning and relevant information [22,23,91]. To facilitate semantic interoperability across different applications, Bishr [92] identified two types of semantic heterogeneity to be addressed, namely, cognitive heterogeneity involving different perspectives of the same phenomena, and naming semantics involving different terminology for the same phenomena. This meaning of phenomena is captured using ontologies, which are knowledge in the form of rules and inferences. Ontologies are represented using a language such as the commonly used Web Ontology Language (OWL), which is part of the Resources Description Framework (RDF) [93,94].

An example of a semantic web solution is the retrieval of public health information from a disparate range of community databases in a case study at the University of Texas [95]. Structured data such as medical records and unstructured data such as doctor's notes were integrated and queried using ontologies that capture health conditions and contextual information with the outcome to obtain perspectives on community health and disease surveillance $[95,96]$. As another example, Zhang et al. [94] describes a prototype for the state of Connecticut that enables emergency responders to automatically search geospatial features from multiple semantically heterogeneous data sources. 
The OWL ontologies enrich the natural language interface that can accept queries from non-expert users without prior knowledge. Users can express queries using their own natural language about roads, town boundaries, airports, etc., and the natural language processing parser will use synonyms from WordNet as well as domain ontologies to make the interpretation and linkage of appropriate information to enable query results interpretation. As a further example, Fa et al. [97] developed a brokered system that uses OWL ontologies to integrate multiple heterogeneous datasets for the purpose of responding to a user query. They tested this for queries on state electoral boundaries across multiple state jurisdictions in Australia.

The developments in the geospatial semantic web include aspects of semantic information representation, automated and semi-automated building of ontologies, semantic web services composition, natural language processing and data discovery, and performance issues [94]. A range of different ontologies needs to be constructed for data, functionality and execution of applications online [98]. In addition to this, intelligence needs to be utilized to apply results of queries to the context of users and applications. Ontologies are also being used to profile users and applications so that additional semantic information regarding query context can be applied. The goal is to provide only relevant information to users and applications in the appropriate context: geographic, temporal, attributed, semantic, historical, etc.

As Web 3.0 continues to evolve, including in the geospatial domain, there continues to be speculation about what future web developments may embrace. The focus is increasingly on the human-machine interaction with increased automated and semi-automated decision-making.

\section{Trends and Directions in Web Mapping}

Each of the web mapping eras described in the previous section identifies one or more significant technological developments that characterize that era. The developments involve technology and users. The developing technology influences accessibility to data by providing a shared platform (Static and Cloud eras), improving the response times to data requests (Dynamic, Services, and Interactive eras), providing a richer interface for data access (Digital Globe, Mobile and Location Based, and Intelligent eras) and enabling data, functionality and services generation (Interactive, Digital Globe, Mobile and Location Based, and Intelligent eras).

By considering the developments and advances across all eras, certain trends can be gleaned giving rise to potential directions that may define the future of web and cloud mapping and GIS. We will first consider some of the trends that can be gleaned from canvassing the developments across all web mapping eras outlined in Section 3.2. These trends are considered from the perspectives of three components identified for web map usage: data, users and functionality. We then outline some directions for web mapping into the future, again from the perspective of these three usage components. Finally, we provide some examples of how these directions might eventuate in a future smart city environment.

\subsection{Trends in Web Map Usage Components}

Obviously, the goal of a web map is to use it. The usage of maps was outlined by MacEachren and Kraak [99] who identified three dimensions of map use, namely, the audience, data relations and user interaction. Veenendaal [100] adapted this model for map use in a web environment and identified the three components influencing web map use to be users, data context and functionality (Figure 5). This model is useful to assist in identifying trends and directions in web mapping, as it identifies the interaction among data, users and functionality in a web environment.

Figure 5 shows that, where little is known of the data context, professional GIS users will need to use high-end GIS functionality to explore and analyze the data. However, with an increasing number of global users having little or no geospatial expertise, there is a need to synthesize and present information in an appropriate and known data context (e.g., information and knowledge) transparently to the user. Hence, these users will not require direct access to high geospatial functionality and will rely 
on the underlying geospatial web processing infrastructures to discover, link, analyze and synthesize information and knowledge for them.

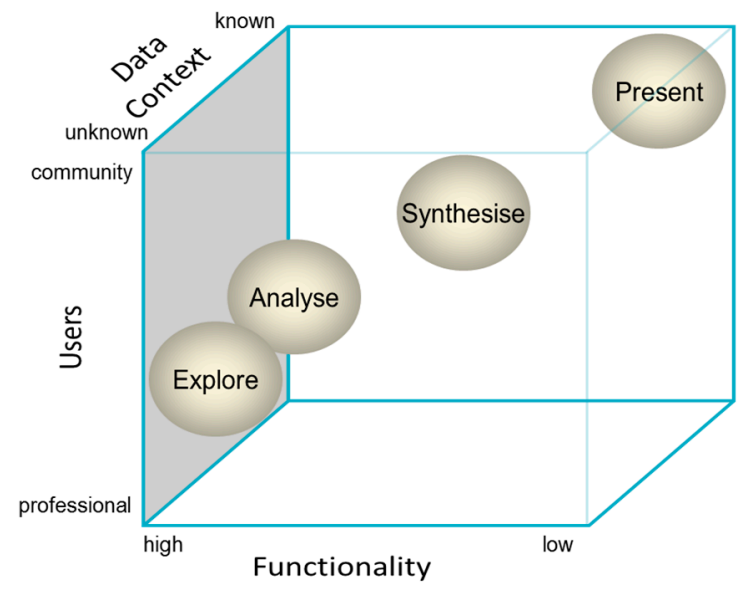

Figure 5. Component dimensions influencing web map use ([100]; Adapted from [99]).

The three components of web map use can be used as a perspective to view the trends in developments among the web mapping eras. Each era has had some impact on one or more of these three components, which in turn has enhanced web mapping. At the same time, each of the three components is necessary for the advancement of web mapping, since they interrelate to enhance web map usage, as is evident by the map use models identified. The following sections discuss the influences and trends among the web mapping eras from the perspective of these three components.

\subsubsection{Web Mapping Data Trends}

In the early eras of web mapping, geospatial data and maps were generated by professionals (e.g., GIS digitizing, surveying, photogrammetry, and remote sensing) and the relatively smaller volumes of data captured were limited by low computer network bandwidths and infrastructure. However, data volumes increased immensely through subsequent eras (e.g., Collaborative, Digital Globe, Mobileand Location-Based, etc.) along with the availability of online satellite imagery web services and the proliferation of users and sensors contributing content. Through the Cloud era, increasingly more data is being captured and stored somewhere online in the cloud and the increasing number of devices online via the IoT is beginning to contribute substantially more data, including location based data, to the web.

According to a Cisco White Paper [101], the amount of data available on the Internet has increased to more than a staggering one billion websites by the end of 2016 [102] with traffic of more than 1 zettabyte (1000 exabytes) per year. The amount of traffic is expected to increase to $2.3 \mathrm{ZB}$ per year by 2020. This includes the trend of data being moved from desktop environments into the cloud as well as the increasing volume of data being captured through mobile, sensor and social media/communication platforms. Of these data, a large proportion is geospatial imagery and features. For example, the amount of Google Earth imagery grew from an estimated 150 TB in 2006 to 3 petabytes in 2016, including aerial, satellite, 2D, 3D and historical imagery [103].

The proliferation of data [104] has led us into the big data era with all the consequent challenges [105]. Big data are characterized by huge volumes, in order of petabytes, huge variability, from unstructured to differently structured data, and huge velocity, having sensors continuously operating and measuring at high temporal frequencies. Some examples, which give some impression of their dimension but do not exhaust the list of possible data sources, are: imagery from unmanned aerial vehicles (UAVs), aircraft, helicopters, satellites, laser scanning, global navigation satellite 
system (GNSS) tracking, mobile mapping, geotagged web content, geolocated communication data, volunteered geographic information (VGI) and geolocated sensors (geoloT).

The European Space Agency with its Sentinel Open Data [106] is complementing the huge amount of free and open available imagery, while some private companies are investing much effort in producing satellite data [107]. A relevant example of the latter case is Planet [108] which currently operates 149 satellites in orbit, with the ability to image all of Earth's landmass every day. Even if we consider only the optical satellite imagery, the Sentinel 2 produces 2 terabytes of data per day, while PlanetScope generates 60 terabytes per day [109].

On the web, not only the quantity of data but also the quality and accessibility to data are influential factors [110]. The quality of data determines whether it is sufficient for purpose, relevant and fit for use. The masses of data must be turned into useful and relevant information from which decision-making occurs. Apparently, the cloud represents the only realistic possibility of dealing with such a data flood and cloud web mapping is rapidly emerging.

As illustrated in the Data, Information, Knowledge, Intelligence and Wisdom (DIKIW) pyramid in Figure 6, to deliver that useful and relevant information, there must be a discovery and integration of all necessary information resources. There needs to be access to appropriate geo-processing services to manipulate and filter the data to suit user or application profiles and contexts. For example, the appropriate data involving land use, roads, drainage, sewerage, water, power, specific covenants on the land, protected lands and easements, must be extracted, linked, integrated, refined and presented to a land developer for the purpose of making decisions about new land developments. This may involve using and building metadata and ontologies for the different data themes and semantically linking them together so that queries and results can be contextualized to the decision-maker. The relatively recent release of HTML5 supports the semantic structure of web documents that will lead to better intelligence around building web page components [111]. These are all relevant aspects of current developments in the intelligent web mapping era.

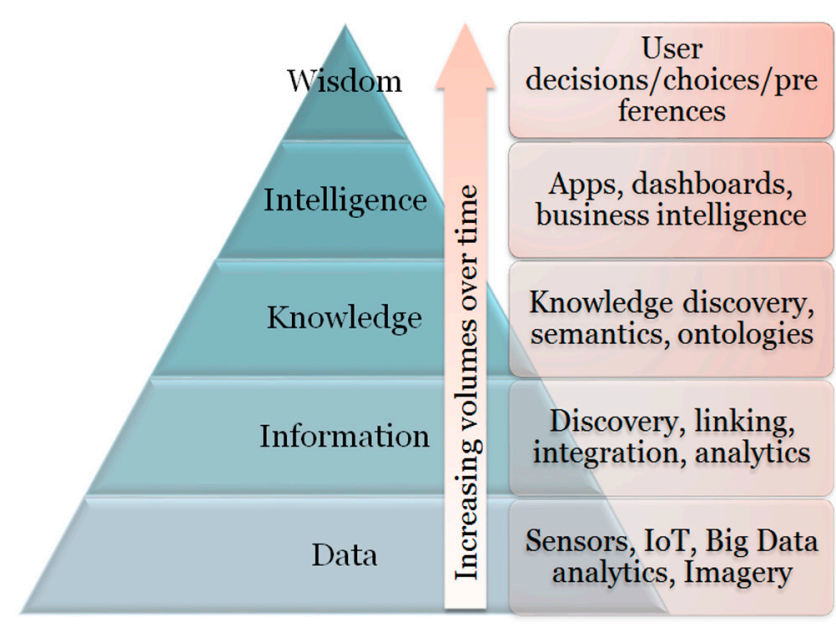

Figure 6. Trends and developments across the DIKIW pyramid.

\subsubsection{Web Mapping User Trends}

Web mapping developments have had and continue to have a strong influence on the number and diversity of users and their ability to use and interact with geospatial and mapping information. Not only has the number of users grown enormously, but also the range in geospatial awareness and literacy, and the way they use geospatial information and collaborate with each other.

The Static era was significant for giving multiple users access to online, shared static maps. Through subsequent eras, particularly the Dynamic and Interactive eras, users were then able to interact with the map for the purposes of customizing it and selecting the information to be visualized. The 
Digital Globe era provided the ability to navigate through a 3D landscape with adequate performance in terms of response times. The Mobile and Cloud eras provided users with the ability to interact with mapping information, functionality, location-based services and GIS from the cloud accessed through personalized and mobile devices, thereby enhancing convenience of access to information in time and place. The advances through the eras also enabled developers to more easily link geospatial data from multiple sources into web maps and facilitate the generation of content by communities and users.

However, the most significant impact of web mapping across the eras is the dissemination of web maps to a huge proliferation of users. Whereas the exposure to web mapping was limited in the early eras to a relatively small group of expert users and developers, the increasing interactivity, opportunities to collaborate and ease of use of 2D and 3D mapping, evidenced in the Interactive, Collaborative and Digital Globe web mapping eras, have caused the explosion of web mapping access by the average citizen and global community. The user base of access to the Internet expanded from the order of thousands to essentially billions in just over two decades (Figure 7).

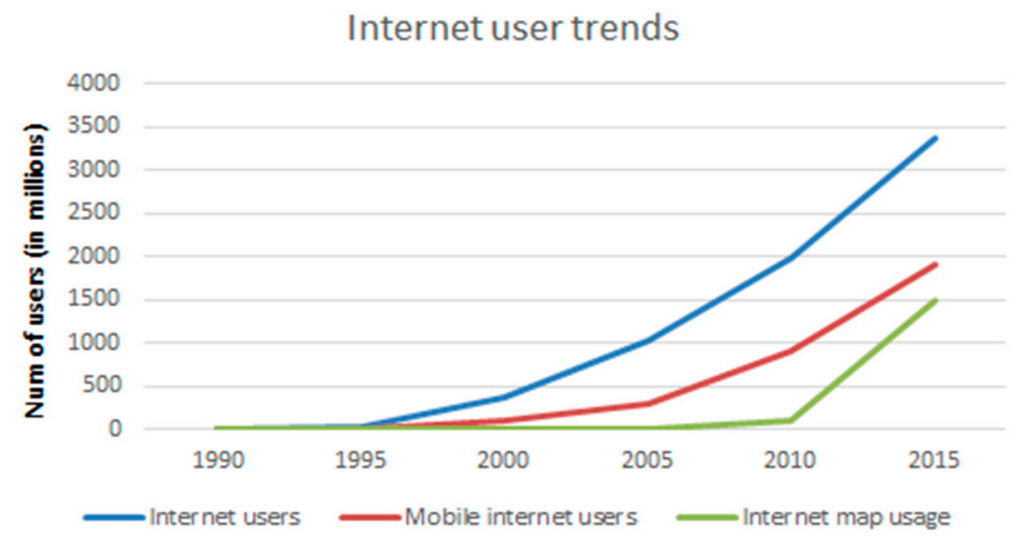

Figure 7. Growth in number of users on the Internet.

For example, by 2008, MapQuest had 45 million users per month accessing online maps [112] and Google Maps had over one billion monthly users in 2014, representing $41 \%$ of Internet users worldwide [113]. The growth in user numbers will taper off as it approaches the world population and reaches a saturation point. Instead, the usage of web mapping by the same number of users, via apps and applications, will increase.

The development and influence of the geospatial web goes well beyond only individuals [18]. Seo and Lee [114] focused on the influence of Web 2.0 technology on organizations and how their user culture that must grow alongside technology developments in order to reap the benefits and take advantage of new opportunities. They compared and analyzed a number of large organizations in terms of their technological and organizational readiness to adopt Web 2.0. In general, where the organization developed a culture and initiatives involving interaction and democracy, in essence the principles underlying Web 2.0, they have obtained better value and performance in adopting Web 2.0 technologies.

The exposure of web mapping to a large number of users and organizations is very significant as it opened up geospatial data and web maps to a very diverse user base across many disciplines and organizations together with a whole range of new applications. The users of maps and geospatial data have expanded beyond the traditional realm of the likes of land managers, natural resources management and infrastructure developers, to users and applications of health, business, education, finance, economics, travel, tourism, etc. This is evidenced by the increasing number of organizations using geospatial information and maps on the web. For example, as of May 2017, there are over five million websites using Google Maps; of the top one million, 80,000 homepages on the web are using Google Maps $[115,116]$. The trends show this number continuing to increase as more 
organizations and applications embed the usage of web mapping and geospatial data into their organizations and web infrastructure.

What can be identified as the possibly the most significant influence of web mapping developments on users is their contribution to enhancing and promoting collaboration. Users could, via online maps and mobile mapping devices, contribute data and information using Web 2.0 technologies, but more importantly, together participate in building and utilizing geospatial information for decision-making. Participatory GIS systems, involving the empowerment of communities through active input, access to and analysis using GIS, were enhanced by online mapping and geospatial analysis. Miller [117] and Plantin [118] outlined how web mapping applications have had a significant positive effect on public participation in mapping. Public users can work collaboratively using online web maps to share and access data as well as be content providers via crowdsourcing and VGIS environments [58].

For example, GISCorps uses a community of volunteers engaged using online GIS to support humanitarian relief, community development, local capacity building, health and education. As of early 2017, they have deployed over 1000 volunteers from 50 countries to use online mapping to collaborate in 198 missions across 66 countries [119]. OpenStreetMap is a further example of a community of geospatial content providers for world data. More than three million contributors have generated almost four billion nodes, 40 million ways and five million relations [120]. Currently, an average of 30,000 active contributors per month generates over 1.5 million new nodes and ways per day in OpenStreetMap, as it can be derived from the OpenStreetMap Statistics Report [121].

Even as early as 2010, Wikimapia had over one million registered users contributing geospatial content [122]. By 2012, there were already over 17 million contributed locations and descriptions [122] with the total number of contributed objects being around 27 million by May 2017 [123].

Although web maps will continue to be used by end users, the trend is in the growth on the number of applications and systems that directly consume geospatial information and services. Geospatial information, semantics and analytics (see Section 4.1.1) will need to be consumed by applications that automatically discover, access, and use it. The end users will benefit from the greater level of knowledge and decision-making that will be undertaken in a semi-automated or even fully automated environment.

\subsubsection{Web Mapping Functionality Trends}

The breadth and complexity of functionality for geospatial data on the web has been developed extensively over the web mapping eras. What started with simple static maps as online images has developed into Web GIS systems with a full range of GIS functionality. Steiniger and Weibel [124] identified three broad GIS functionality categories, namely: viewing, editing and analyzing. GIS software, including both desktop and web-based, provide functionality across all three categories, whereas other software including map viewers, mobile field map data capture, and basic web map clients may implement functionality across only one or two categories [124]. Initially, web mapping systems were focused on the viewing functionality, and with the development of supporting technology, expanded to include editing and, more recently, analytic functionality.

In the static web mapping era, the focus of web mapping was primarily on viewing maps and providing some basic options for viewing. The Xerox Parc map [16] essentially provided users with a range of map images selected by choosing from some basic options for zooming, panning, coordinate systems and display layers using hyperlinks. The era of dynamic maps more closely represented map views that were more akin to those of GIS. The web mapping services era opened the way for map servers to provide not just map image services but also geospatial data and processing services. This enabled GIS functionality to be provided online, as was the case for MapQuest that implemented routing and navigation functionality with its online mapping [112]. Together with the developments during the Interactive and Collaborative web mapping eras, users were able to not only retrieve but also capture, edit, store and analyze geospatial data using asynchronous client/server technologies. 
The digital globe developments brought in tiled imagery into highly interactive 2D and 3D geo-browsers. While initially focused on viewing, the digital globe geo-browsers have been developed to include geospatial data editing, integration from various sources and basic GIS queries [125-127]. Examples related to advanced virtual globes include the analysis of Earthquake Signal Precursors [128], visualization and analysis of doxels data models [62], processing of satellite images for environmental analyses [83], and virtual high-speed railway 3D models [129].

The development of technologies such as CSS, AJAX and HTML enabled applications on web browsers to have the same functionality as those on desktop computers [130]. This, together with the cloud SAAS developments, has encouraged people to move from a desktop environment into the web environment using the Internet and cloud. They require access to similar functionality in a recognized and friendly environment tailored to their purpose of use. Examples of this include Google Docs on Google Drive and Microsoft Office on One-Drive, where documents are shared, edited and tracked in the cloud in real time among collaborators.

The developments in cloud-based technology, providing the infrastructure to host both data and functionality online, brought rapid developments in web mapping as well as Web GIS. By implementing an architecture of web database and geoprocessing services in the cloud, a wider range of GIS functionality could be integrated within a true Web GIS online platform that became more accessible to a broader range of global users [131]. Cloud services provide functionality for everything from data sensor retrieval and information extraction to knowledge and ontology discovery; more and more data, information, and knowledge will be accessed by and serve functional web services online (Figure 8).

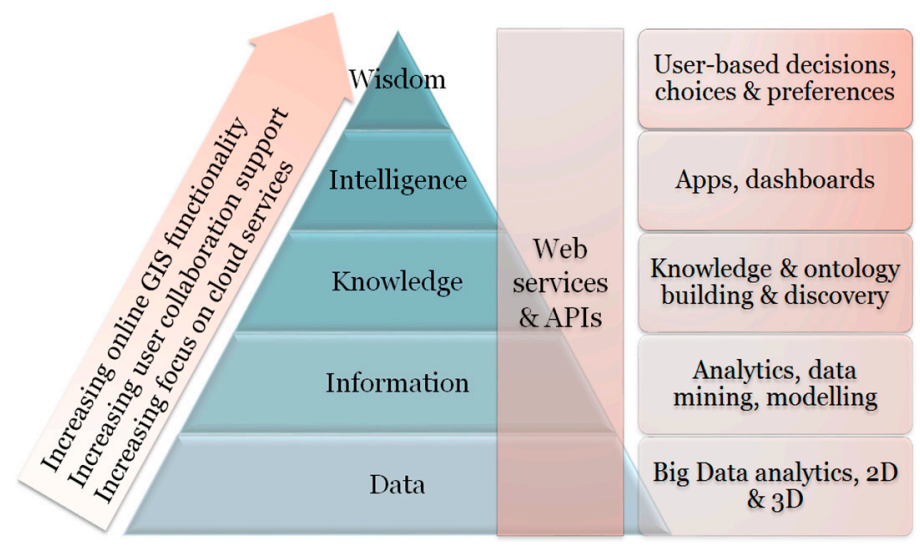

Figure 8. Focus and trends in increasing web mapping functionality.

The Web GIS environments currently have similar, although reduced, functionality and interfaces to the desktop GIS environments, although the distinctions are becoming less. There is a trend towards greater support, integration with and uptake of the online environment by GIS functionality. Open source and vendor based developments include MapServer, GeoServer, ArcGIS Online, AspMap, GeoNode, GeoShape and QGIS Cloud. Through their exposure on the web to a broader community of developers, many of these GIS and mapping functionalities are becoming embedded into web interfaces for global community users, among whom geospatial information and maps are just another information resource. These emerging online mapping and GIS environments are beginning to provide more support for increased user sharing, collaboration and team-based content provision, including real-time shared environments that synchronize map sharing and geo-processing by collaborators at different locations at the same time [132].

For example, ArcGIS Online [133] was released in 2012 and initially provided users with a simple online GIS interface to create, visualize, manipulate and customize maps that could be mashed up from various map sources and services. Subsequently, the online cloud environment expanded to include 
GIS and spatial analytics functionality. Users can add and build data, maps, 3D scenes, analytics and apps in the cloud and integrate with the content from ESRI's Living Atlas of the World combining ESRI and user community resources. Users can publish, collaborate with and share their mapping data and analytics resources with other users and applications in desktop and mobile environments. A further development is the release in 2015 by ESRI of ArcGIS Pro which is a redesigned GIS suite integrating the desktop and online environments with sharing and collaboration between ArcGIS Enterprise, ArcGIS Online and ArcGIS Pro [134]. The integration of online platforms into desktop environments is part of the increasing trend towards cloud-based mapping.

A second example is GeoNode. Its development commenced in 2009 with work between the Global Facility for Disaster Reduction and Recovery of World Bank and other partners [135]. As a web-based, open source software under GPL licenses, it enables organizations and general users to easily create catalogs of geospatial data, and to access, share, and visualize data, associated metadata, documents, permissions and maps. Further developments for GeoNode using interoperability and available open source tools such as GeoGig [136] and the GeoTools libraries, lead to this software evolving into a fully distributed and online GIS. As an example, the UN OpenGIS Initiative Platform can be found in Eom [137].

Through the intelligent web mapping era, which is still the current era, there are substantial developments still being researched and developed to build and manipulate ontologies to support information discovery, retrieval, linkage, interoperability, integration and querying (refer to Section 3.2.9). The trend is towards increased automation in the construction of ontologies that can then be used in generating knowledge and gleaning insight into specific application/business processes. The resulting knowledge and insight are being captured and integrated into apps and dashboards that provide summaries, snapshots, analytics and scenarios of current business and application processes (Figure 8). This intelligence and insight is then being used by end users for decision-making and in the context of particular preferences and choice sets or determined by the users.

\subsection{Directions in Web Mapping: Data, Users and Functionality}

The volumes of data being captured as well as the transition from data to knowledge, the proliferation of users and applications, and the expansion of online GIS and mapping functionality have implications for web mapping and Web GIS developments into the future. Firstly, the increasing volumes of data, information and knowledge being captured and derived drive the need for increased management, functionality, analytics and modeling. The purpose is to extract the relevant and useful information to applications and users that manage and make decisions. This in turn drives increased user and application expectations regarding the level and contextualization of information and knowledge to the task at hands. The enhanced and relevant access to high-level knowledge enables more users and applications. This in turn continues the cycle of the ever-expanding intelligent geospatial world in which we live.

Thus, what does this mean for the directions and future of web mapping and geospatial applications? The following sections explore possible and potential directions based on the trends in data, users and functionality as outlined in Section 4.1.

\subsubsection{Directions for Web Mapping Data}

The amount of data and information on the web is continuing to proliferate with sources including aerial and satellite imagery, crowdsourced data, online databases, sensors, data feeds from Internet-enabled objects in the Internet of Things (IoT) and online social interactions [138-140]. By 2025, there is expected to be 27 billion connected devices on the Internet with one-third critically dependent on geolocation data and 60\% potentially including geospatial data in applications [141].

Once collected, all that data have to be made available and contextualized for extracting information and then knowledge. If the Internet and the cloud could be the glue for sharing, many steps have to be considered to make this availability efficient and effective. The heterogeneous data 
has to be modeled, structured, and indexed. Mechanisms for discovering and mining them have to be implemented or enriched. The additional benefits of the availability of such diverse and different sources of data, as well as understanding their quality and limitations, is crucial in promoting their integration including the capacity of dealing with both syntactic and semantic procedures, based on ontologies and workflows (refer to Section 4.2.3 for more on this).

Data will be so important in the next years that "Organizations that do not use data intelligently, will not survive" [90]. That is the reason why a relatively new professional, the data scientist, is a key player in making mashups of multiple analytical processes to make sense of petabytes of big data [142]. Web mapping will continue to be a strong component in data science, since location (space/time) is a fundamental key for contextualizing events and visualization will remain one of the strongest tools for interpreting and linking data, information, knowledge and intelligence.

\subsubsection{Directions for Web Mapping Users}

With the approaching worldwide saturation of the number of users of the geospatial web, the future is not in an increasing number of users, but in an increasing number of applications being used by these users. More and more applications and apps from a greater diversity of disciplines will consume geospatial information that is integrated within their business and consumer workflows and decision-making processes. The challenge for future developments is to provide information and knowledge in an integrated, contextualized and even automated environment that makes it easy and transparent to consume.

Thus, what will this integrated and contextualized environment look like? A number of characteristics can help define this environment, namely, authentic, collaborative and personalized. This means users will engage with and be immersed in an environment that they can relate to and that is relevant to their problem or decision-making. They will be able to engage with others and collaborate in joint projects and tasks irrespective of their geographic location. They will have access to the information that is relevant to their queries and tasks at hands.

To be authentic, the geospatial web environment must engage and immerse users in a realistic $3 \mathrm{D}$ and $4 \mathrm{D}$ experience involving real world processes, problem solving and decision-making [143]. For example, Craglia et al. [144] envision a future Digital Earth to provide users with the world's information, multidimensional in space and time, above, on and below the surface, integrating both physical and virtual spaces, and incorporating more than simply space and spatial relations, but at a higher level, places, culture and identity together with their interrelationships. Digital Earth will be able to engage users with historical perspectives and developments as well as explore models that provide scenarios, explain processes or assist in predicting the future. Users will have greater control over contributing data, interpreting information, building scientific models and shaping policy choices and decisions. Craglia et al. [144] also indicate that Digital Earth should be easy to use, fun and interactive, irrespective of the user's skills and level of knowledge.

The geospatial web will become increasingly collaborative with users being able to work together in both physical and virtual environments. Li et al. [143] point to a more collaborative and social environment in which users are engaged in shared applications in space and time. The future Digital Earth will likewise be more participative with users being able to interact and share experiences in a realistic digital globe environment [144].

The geospatial web environment will also become more personalized to users in the future. It is personalized for users both in the sense that users can guide and control what they want to see or know, but also in a transparent way based on appropriately filtered and contextualized information using user profiles and history. Personalization involves knowing both the requirements of users as well as the requirements for applications and tasks they are engaged with. Users with varying backgrounds and skill levels from diverse disciplines and with different perspectives will be able to converse and engage in an integrated, personalized and semantically-rich environment [93]. 


\subsubsection{Directions for Web Mapping Functionality}

In addition to the closer integration currently taking place between desktop and cloud environments, for example ArcGIS Pro (Section 4.1.3), there is an increasing transition towards the cloud with greater functionality being delivered online. In fact, the distinction between desktop and online will disappear as all software, data and devices, including sensors, will essentially be online with decisions made about what gets stored permanently or temporarily in the cloud and on local (fixed or mobile) devices. Hence, there will be more Web GIS, and extended offerings using the cloud for both data and functionality to be delivered to a range of applications on fixed and mobile devices.

To be able to support the increased functionality and analytics, as with data (refer to Section 4.2.1), the GeoWeb and underlying network infrastructure will need to expand and be further developed. Developments will need to accommodate such aspects as the increasing parallel processing capacity in cloud environments, big spatial data analytics, and online collaborative workflows. Some of these issues are currently being researched, for example, for query driven visual exploration environments [145] and global land use cover integration, quality verification and production workflows [146].

However, such functionality will not only be based on what we currently perceive as GIS capability, but also being online, which will need to be integrated directly into applications workflows and business processes. In essence, such functionality needs to bridge the gap between the technology and end users, between information manipulation and business processes, between data and knowledge. Issues such as interoperability of geospatial models through web services, security and privacy, integration into workflows, automated service composition etc., will need to be addressed. Interfaces for a diverse range of users (e.g., developers, professionals, decision-makers) will need to be explored and developed. This will need to enhance the user experience by being embedded in their views, activities, workflows, etc., in a manner that is relevant, adaptive, personalized and not disruptive, inconsistent or overbearing. Users want to maintain control and have information filtered to their specific needs. Further developments will need to occur in such areas as virtual reality, augmented reality, wearable devices and the linking of multiple devices with users and activities. An example is the development of smart watches with GPS and heart rate sensors, for monitoring a person's fitness activities and movements and linked to their smart phone to provide analytics and health advice on-the-fly.

With the proliferation of captured data comes the challenge to extract information and knowledge that is useful to users and applications for tasks and decision making. This will require further development in data mining, knowledge discovery and extraction, machine learning and geocomputational techniques and modeling. The Cooperative Research Centre for Spatial Information outlines some of these directions in a white paper outlining a spatial knowledge infrastructure [147]. They particularly identify the need for research into the sharing, versatility, process and usability of data, information and knowledge. This information and knowledge must be further manipulated, filtered and contextualized according to user and application requirements and contexts. An increasing effort will need to be put into constructing, representing and manipulating semantics in the form of ontologies that add meaning to data and information. Computing software needs to automate ontology construction and maintain user and application profiles (also represented as ontologies). The resulting knowledge will be fed by big data analytics, modeling outcomes and combined with other knowledge to produce intelligence. The functionality available online needs to expand beyond data and information to encompass discovery, retrieval, extraction, integration, construction, analysis, modeling, etc. of knowledge and intelligence. The challenge is to determine what high-level functionality is required to achieve this in the context of applications and end users.

How will this functionality be organized into the online cloud environment? Rather than the "software package" concept, which has a particular scope and focus based on its origin in desktop environments, the online environment will expand to comprise a greater diversity of low-level and high-level software components that can be dynamically retrieved and integrated easily by web 
development environments into an application or in response to a query. Bouguettay et al. [148] identify a service-computing environment with a new paradigm of web services, beyond the currently existing low-level web services regime, that integrates online software components and devices to build modular software applications and deliver services at a higher level of abstraction. The data and services captured at the lower end are transformed into information and knowledge web services using ontologies and analytics (Figure 9). The results are a range of high-level web services feeding directly into apps on fixed and mobile devices, within application workflows. The goal is to bridge the gap between information technology and business services for the users and applications.

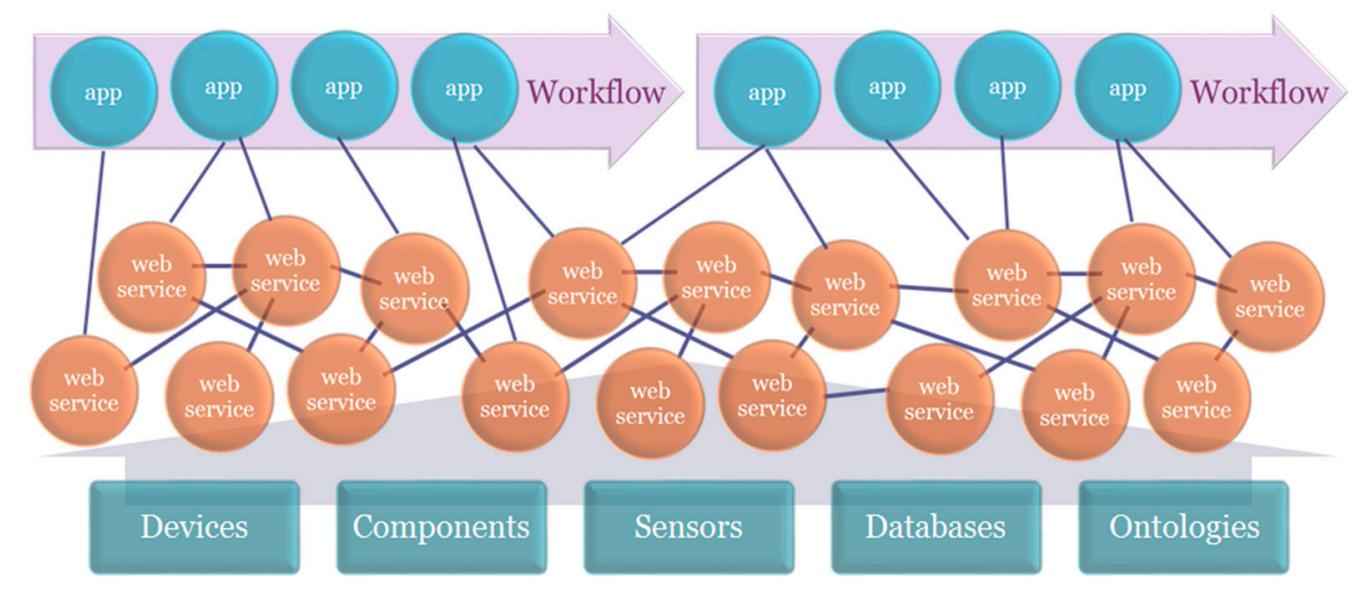

Figure 9. Interacting web services feeding into apps within application workflows.

In geospatial terms, there will be high-level business, decision oriented, context-aware, and cloud-based services embedded within application workflows. These high-level services integrate a range of web services and resources including geospatial software components, mobile devices, IoT sensor data, big data computing, cloud computing and social computing. In fact, the building of (high-level) services from other services will require further research into automated online services composition to scalable and adaptive solutions that take advantage of the diverse data sources, big data analytic requirements, social and application context and mobile device environments [148]. These high level services offering information, knowledge and intelligence will need to be embedded in interfaces and workflows customized and personalized to specific users and diverse audiences. The building of these complex interfaces fed by high level services will require much effort and costs that will need to be balanced with the increased cognitive complexities and benefits gained in productivity and insights.

To enable automation of the composition of functional web services, functionality ontologies will need to be built to represent the appropriate functional semantics and execution semantics [98]. The application workflows, supported by automated functions and services utilizing embedded semantics to discover, link and integrate knowledge, will serve end users who need not be experts but will set preferences, make choices and decisions, and take action as necessary in responding to their intelligent environment.

\section{Conclusions}

Web mapping has evolved rapidly over the past three decades and refers to many different capabilities enabling users to interact with geospatial data represented by maps. The nine web mapping eras provide a framework in which to identify the significant developments and influences over the history of web mapping. These include not only technological advances but also the influences on a dramatically increased number of users and usage. This framework can also be used to organize 
web mapping curricula in educational programs, as was done by the lead author within the geographic information science curricula.

A number of trends were identified throughout the web mapping areas, notably in regards to data, users and functionality. Not only is the volume of data continuing to increase dramatically via sensors and user-generated content, but also the quality and semantics are increasing the levels of information, knowledge and intelligence being generated and applied to application workflows and decision-making. The numbers of users of web mapping have dramatically increased in the past few years, influencing and being influenced by easier access, greater diversity and applications that are more integrated and intelligent. Increasing geospatial functionality is being incorporated into Web GIS environments that provide a collaborative online environment supporting users and applications.

The directions in web mapping are towards more intelligent capture and use of data in analytics and knowledge generation for a diverse user and application base. Increasingly higher levels of information identified in the DIKIW pyramid are required—-knowledge underpinned by semantics and linked data. Users continually want better information, focused and filtered to their needs and customized to their level of knowledge and skills. This means that web mapping and GIS systems and services will need to be more intelligent, efficient and focused to support users and applications at the knowledge, intelligence and wisdom levels. That also means there will need to be a greater level of semantics defined and representation of knowledge to feed higher levels of the information pyramid. Insights can be gleaned from a range of knowledge and wisdom applied through automated or semi-automated workflows in which decision-making is user-driven in context.

This brings about the need of providing richer environments for developing, using and visualizing maps and geospatial information in the context of business processes and high-level workflows within and across applications. This enables a spiral of geospatial information access and provision, where contextualized and better information, utilized by more users and applications, leads to greater demands and requirements that need to be met by further technological developments, increased functionality and greater contextualization of information.

Acknowledgments: This work has been partially funded by the Italian MIUR PRIN 2015 Project “URBAN GEOmatics for Bulk Information Generation, Data Assessment and Technology Awareness", and the Natural Science and Engineering Research Council of Canada (NSERC) project RGPIN-2017-05950. The authors appreciate the feedback from web mapping students who used the framework in their curriculum, and would like to thank anonymous reviewers for their constructive comments, which helped improve the paper.

Author Contributions: Bert Veenendaal wrote the first draft of this review. All authors contributed to intensive discussions, writing of various sections, revisions and finalizing of the manuscript.

Conflicts of Interest: The authors declare no conflict of interest.

\section{References}

1. Gore, A. The digital earth: Understanding our planet in the 21st century. Aust. Surv. 1998, 43, 89-91. [CrossRef]

2. Goodchild, M.F.; Guo, H.; Annoni, A.; Bian, L.; de Bie, K.; Campbell, F.; Craglia, M.; Ehlers, M.; van Gendern, J.; Jackson, D.; et al. Next-generation digital earth. Proc. Natl. Acad. Sci. USA 2012, 109, 11088-11094. [CrossRef] [PubMed]

3. V1 Media. How Far Have We Progressed against the Digital Earth Vision? 2016. Available online: http: / / sensorsandsystems.com/how-far-have-we-progressed-against-the-digital-earth-vision/ (accessed on 8 July 2017).

4. Hall, W.; Tiropanis, T. Web evolution and Web science. Comput. Netw. 2012, 56, 3859-3865. [CrossRef]

5. Hess, S. GRASS on the Web. In Proceedings of the Open Source GIS-GRASS Users Conference 2002, Trento, Italy, 11-13 September 2002; pp. 1-14.

6. Neumann, A. Web Mapping and Web Cartography. In Encyclopedia of GIS; Shekhar, S., Xiong, H., Eds.; Springer: Berlin, Germany, 2008; pp. 1261-1270.

7. Techopedia. Web Mapping. Available online: https://www.techopedia.com/definition/15584/webmapping (accessed on 11 July 2017). 
8. Wikipedia. Web Mapping. Available online: https://en.wikipedia.org/wiki/Web_mapping (accessed on 12 July 2017).

9. Peng, Z.R.; Tsou, M.H. Internet GIS: Distributed Geographic Information Services for the Internet and Wireless Networks; John Wiley \& Sons: Hoboken, NJ, USA, 2003; ISBN 978-0-471-35923-4.

10. Fu, P.; Sun, J. Web GIS: Principles and Applications; ESRI Press: Redlands, CA, USA, 2011; ISBN 9781589482456.

11. Haklay, M.; Singleton, A.; Parker, C. Web mapping 2.0: The neogeography of the GeoWeb. Geogr. Compass 2008, 2, 2011-2039. [CrossRef]

12. Veenendaal, B.; Brovelli, M.A.; Li, S.; Ivánová, I. What is Web Mapping Anyway? Int. Arch. Photogramm. Remote Sens. Spat. Inf. Sci. 2017, 42, 155-160. [CrossRef]

13. McIhagga, D. Chapter 3: Communities of Practice and the Business of Open Source Web Mapping. In Open Source Approaches in Spatial Data Handling. Advances in Geographic Information Science; Hall, G.B., Leahy, M.G., Eds.; Springer: Berlin/Heidelberg, Germany, 2008; Volume 2, pp. 49-64.

14. Hardie, A. The Development and Present State of Web-GIS. Cartography 1998, 27, 11-26. [CrossRef]

15. Batty, M.; Hudson-Smith, A.; Milton, R.; Crooks, A. Map mashups, Web 2.0 and the GIS revolution. Ann. GIS 2010, 16, 1-13. [CrossRef]

16. Xerox. Xerox PARC Map Viewer. 2013. Available online: http://www.inwap.com/inwap/chez/parc-map. html (accessed on 12 May 2015).

17. Putz, S. Interactive information services using World-Wide Web hypertext. Comput. Netw. ISDN Syst. 1994, 27, 273-280. [CrossRef]

18. Veenendaal, B. Eras of web mapping developments: Past, present and future. In Proceedings of the International Archives of the Photogrammetry, Remote Sensing and Spatial Information Sciences 2016, Prague, Czech Republic, 12-19 July 2016; Volume XLI-B4, pp. 247-252.

19. Choudhury, N. World Wide Web and its journey from web 1.0 to web 4.0. Int. J. Comput. Sci. Inf. Technol. 2014, 5, 8096-8100.

20. Berners-Lee, T. The World Wide Web: A Very Short Personal History. Available online: http://www.w3.org/ People/Berners-Lee/ShortHistory.html (accessed on 8 July 2017).

21. O'Reilly, T. O'Reilly Media. What Is Web 2.0: Design Patterns and Business Models for the Next Generation of Software. Available online: http:/ / www.oreilly.com/pub/a/web2/archive/what-is-web-20.html (accessed on 10 July 2017).

22. Berners-Lee, T.; Hendler, J.; Lassila, O. The semantic web. Sci. Am. 2001, 284, 28-37. [CrossRef]

23. Palmer, S.B. The Semantic Web: An Introduction. Available online: http://infomesh.net/2001/swintro (accessed on 9 July 2017).

24. Benito-Osorio, D.; Peris-Ortiz, M.; Armengot, C.R.; Colino, A. Web 5.0: The future of emotional competences in higher education. Glob. Bus. Perspect. 2013, 1, 274-287. [CrossRef]

25. Kambil, A. What is your Web 5.0 strategy? J. Bus. Strategy 2008, 29, 56-58. [CrossRef]

26. Tsou, M.T. Geospatial World. Recent Developments in Internet GIS. 2009. Available online: https: / /www. geospatialworld.net/article/recent-developments-in-internet-gis / (accessed on 12 July 2017).

27. Plewe, B. Web cartography in the United States. Cartogr. Geogr. Inf. Sci. 2007, 34, 133-136. [CrossRef]

28. Tsou, M.T. Revisiting Web Cartography in the United States: The Rise of User-Centered Design. Cartogr. Geogr. Inf. Sci. 2013, 38, 250-257. [CrossRef]

29. Dictionary.com. Era. Available online: http:/ / www.dictionary.com/browse/era (accessed on 8 July 2017).

30. Internet Archive WayBackMachine. Example Showing the Default World Map View. Available online: http: / / web.archive.org/web/20060717213750/; http:/ / www2.parc.com/istl/projects/www94/mapviewerexample1.html (accessed on 12 July 2017).

31. Natural Resources Canada. About the Atlas of Canada. Available online: http:/ /www.nrcan.gc.ca/earthsciences / geography/atlas-canada/about-atlas-canada/16890 (accessed on 10 July 2017).

32. Nebert, D.D. Serving Digital Map Information through the World Wide Web and Wide-Area Information Server Technology; U.S. Geological Survey: Reston, VA, USA, 1995.

33. Quinn, S. Penn State College of Earth and Mineral Sciences. GEOG 585: Open Web Mapping. Available online: https: / www.e-education.psu.edu/geog585/ (accessed on 9 July 2017).

34. Detwiler, J.; Dutton, J.A. Penn State Open Education Resources. GEOG 863-GIS Mashups for Geospatial Professionals. Available online: https:/ / www.e-education.psu.edu/geog863/ (accessed on 8 July 2017).

35. OpenLayers. Available online: http:/ / openlayers.org/ (accessed on 10 July 2017). 
36. Leaflet. Available online: http:/ / leafletjs.com/ (accessed on 8 July 2017).

37. D3.js. Available online: https://d3js.org/ (accessed on 20 July 2017).

38. Google Maps API. Available online: https:/ / developers.google.com/maps (accessed on 10 July 2017).

39. Microsoft Bing Maps. Available online: https://www.microsoft.com/maps/Default.aspx (accessed on 10 July 2017).

40. ESRI. ArcGIS API for JavaScript. Available online: https://developers.arcgis.com/javascript (accessed on 8 July 2017).

41. Boundless Suite. Available online: http://suite.opengeo.org/docs/latest/processing/wpsclient/index.html (accessed on 7 July 2017).

42. Levergood, B.U.S. Census Bureau: The official statistics web site. Gov. Inf. Q. 1998, 15, 147-151. [CrossRef]

43. USCB TIGERweb. Available online: https://tigerweb.geo.census.gov/tigerwebmain/TIGERweb_main.html (accessed on 12 July 2017).

44. MapQuest. Available online: https:/ / www.mapquest.ca/ (accessed on 7 July 2017).

45. Huse, S.M. GRASSLinks: A New Model for Spatial Information Access in Environmental Planning; University of California: Berkeley, CA, USA, 1995.

46. Bernard, L.; Kanellopoulos, I.; Annoni, A.; Smits, P. The European geoportal-One step towards the establishment of a European Spatial Data Infrastructure. Comput. Environ. Urban Syst. 2005, 29, 15-31. [CrossRef]

47. Open Geospatial Consortium. Web Map Service. Available online: http://www.opengeospatial.org/ standards/wms (accessed on 21 September 2017).

48. Open Geospatial Consortium. Web Feature Service. Available online: http://www.opengeospatial.org/ standards/wfs (accessed on 21 September 2017).

49. Open Geospatial Consortium. Web Coverage Service. Available online: http:/ /www.opengeospatial.org/ standards / wcs (accessed on 21 September 2017).

50. Open Geospatial Consortium. Web Processing Service. Available online: http://www.opengeospatial.org/ standards /wps (accessed on 21 September 2017).

51. Garrett, J. Adaptive Path. Ajax: A New Approach to Web Applications. Available online: http: / / adaptivepath.org/ideas/ajax-new-approach-web-applications (accessed on 10 July 2017).

52. Wood, J.; Dykes, J.; Slingsby, A.; Clarke, K. Interactive visual exploration of a large spatio-temporal data set: Reflections on a geovisualization mashup. IEEE Trans. Vis. Comput. Graph. 2007, 13, 1176-1183. [CrossRef] [PubMed]

53. Li, S.; Gong, J. Mashup: A new way of providing web mapping/GIS services. In Proceedings of the International Archives of the Photogrammetry, Remote Sensing and Spatial Information Sciences, Beijing, China, 3-11 July 2008; pp. 639-648.

54. DiNucci, D. Fragmented future. Print 1999, 53, 221-222.

55. O'Reilly, T.; Battelle, J. Web Squared: Web 2.0 Five Years On (Special Report). Available online: https: / / assets.en.oreilly.com/1/event/28/web2009_websquared-whitepaper.pdf (accessed on 10 July 2017).

56. Haklay, M.; Weber, P. Openstreetmap: User-generated street maps. IEEE Pervasive Comput. 2008, 7, 12-18. [CrossRef]

57. Wikimapia. Wikimapia History. 2012. Available online: http://wikimapia.org/history (accessed on 12 July 2017).

58. Goodchild, M.F. Citizens as sensors: The world of volunteered geography. Geo J. 2007, 69, 211-221. [CrossRef]

59. Cesium. WebGL Virtual Globe and Map Engine. Available online: https://cesiumjs.org/ (accessed on 20 July 2017).

60. G3M. Glob3 Mobile SDK. Available online: http://glob3mobile.com/ (accessed on 20 July 2017).

61. osgEarth. Geospatial SDK for OpenSceneGraph. Available online: http://osgearth.org/ (accessed on 20 July 2017).

62. Google. Google Earth VR. Available online: https:/ /vr.google.com/earth (accessed on 18 October 2017).

63. Pirotti, F.; Brovelli, M.A.; Prestifilippo, G. An open source virtual globe rendering engine for 3D applications: NASA World Wind. Open Geospat. Data Softw. Stand. 2017, 2, 4. [CrossRef]

64. Covey, N. Nielsen. Critical Mass: The Worldwide State of the Mobile Web. 2008. Available online: http:/ / www.mmaglobal.com/files/uploads/NielsenMobile_Mobile\%20Internet_Critical\%20Mass_ July\%202008.pdf (accessed on 8 July 2017). 
65. Peterson, M.P. Mapping in the Cloud; Guilford Press: New York, NY, USA, 2014; ISBN 978-1-4625-1041-2.

66. Fu, P. Getting to Know Web GIS, 2nd ed.; ESRI Press: Redlands, CA, USA, 2016; ISBN 9781589484634.

67. Longley, P.A.; Goodchild, M.; Maguire, D.J.; Rhind, D.W. Geographic Information Systems and Science, 4th ed.; Wiley: Hoboken, NJ, USA, 2015; ISBN EHEP003247.

68. Prylutskyi, O. $50^{\circ}$ North. 8 Mobile Geodata Collectors for Android. Available online: http://www. 50northspatial.org/8-mobile-geodata-collectors-android (accessed on 9 July 2017).

69. Loreto V.; Haklay M.; Hotho, A.; Servedio, V.; Stumme, G.; Theunis, J.; Tria, F. Participatory Sensing, Opinion and Collective Awareness; Springer International Publishing: Cham, Switzerland, 2017; ISBN 978-3-319-25658-0.

70. Brovelli, M.A.; Kilsedar, C.E.; Zamboni, G. Visualization of VGI data through the new NASA World Wind Virtual Globe. In Proceedings of the International Archives of the Photogrammetry, Remote Sensing and Spatial Information Sciences, Prague, Czech Republic, 12-19 July 2016; Volume XLI-B4, pp. 205-209. [CrossRef]

71. Geocaching Australia. Available online: http://geocaching.com.au (accessed on 18 October 2017).

72. Foursquare. About Us. 2017. Available online: http:/ / foursquare.com/about (accessed on 18 October 2017).

73. Niantic. Pokemon Go. 2016. Available online: http:// pokemongo.com (accessed on 18 October 2017).

74. Yan, W.Y.; Shaker, A.; El-Ashmawy, N. Urban land cover classification using airborne LiDAR data: A review. Remote Sens. Environ. 2015, 158, 295-310. [CrossRef]

75. Open Geospatial Consortium. Why Is the OGC Involved in Sensor Webs? Available online: http:/ / www. opengeospatial.org/domain/swe\#initiative (accessed on 10 July 2017).

76. Yang, C.; Goodchild, M.; Huang, Q. Spatial cloud computing: How can the geospatial sciences use and help shape cloud computing? Int. J. Digit. Earth 2011, 4, 305-329. [CrossRef]

77. Lee, J.G.; Kang, M. Geospatial Big Data: Challenges and Opportunities. Big Data Res. 2015, 2, 74-81. [CrossRef]

78. White, T. Hadoop: The Definitive Guide, Storage and Analysis at Internet Scale, 4th ed.; O'Reilly Media: Newton, MA, USA, 2015.

79. Thusoo, A.; Sarma, J.S.; Jain, N. Hive: A warehousing solution over a map-reduce framework. In Proceedings of the 35th Conference of Very Large Data Base VLDB Endowment, Lyon, France, 20-23 August 2009; pp. 1626-1629.

80. Hows, D.; Plugge, E.; Membrey, P. The Definitive Guide to MongoDB: A Complete Guide to Dealing with Big Data Using MongoDB, 3rd ed.; Apress: New York, NY, USA, 2015; ISBN 978-1-4302-5822-3.

81. Duan, Y.; Fu, G.; Zhou, N. Everything as a Service (XaaS) on the Cloud: Origins, Current and Future Trends. In Proceedings of the IEEE 8th International Conference on Cloud Computing, New York, NY, USA, 27 June-2 July 2015; pp. 621-628.

82. ESA. SentiNel Application Platform. Available online: http://step.esa.int/main/toolboxes/snap/ (accessed on 8 July 2017).

83. Johnson, M. Google Cloud Platform Blog. Startup Spotlight: Descartes Labs Monitors Planet Earth's Resources with Google Compute Engine. Available online: https:/ / cloudplatform.googleblog.com/2015/ 11/startup-spotlight-Descartes-Labs-monitors-planet-Earths-resources-with-Google-Compute-Engine. html (accessed on 10 July 2017).

84. Mapstory. What Is Mapstory. Available online: https://www.youtube.com/watch?v=HLz552QV46w (accessed on 10 July 2017).

85. WorldMap. Harvard University. Available online: https://about.worldmap.harvard.edu/ (accessed on 13 July 2017).

86. Masdap. Malawi Spatial Data Platform. A Public Platform for GIS Data to Support Development in Malawi. Available online: http:/ / www.masdap.mw/ (accessed on 10 July 2017).

87. Liang, S.H.L. Sensor Networks, the Sensor Web, and the Internet of Things. In International Encyclopedia of Geography: People, the Earth, Environment and Technology; John Wiley \& Sons, Ltd.: Chichester, UK, 2017; pp. 1-17. [CrossRef]

88. Pal, K. Techopedia. What are the Top Driving Forces for the Internet of Things (IoT)? Available online: https: / www.techopedia.com/2/31275/trends/big-data/what-are-the-top-driving-forces-for-theinternet-of-things-iot (accessed on 9 July 2017). 
89. Lundquist, C. TechTarget IoT Agenda. Location of things: Why Location Matters in IoT. Available online: http:/ / internetofthingsagenda.techtarget.com/blog/IoT-Agenda/Location-of-things-Why-locationmatters-in-IoT (accessed on 10 July 2017).

90. Van der Aalst, W.M.P. Data Scientist: The Engineer of the Future. In Enterprise Interoperability, 6th ed.; Mertins, K., Bénaben, F., Poler, R., Bourrières, J.P., Eds.; Springer: Cham, Switzerland, 2016; pp. 13-26. [CrossRef]

91. Berners-Lee, T. Semantic Web Road Map. Available online: http://www.w3.org/DesignIssues/Semantic. html (accessed on 8 July 2017).

92. Bishr, Y. Overcoming the semantic and other barriers to GIS interoperability. Int. J. Geogr. Inf. Sci. 1998, 12, 299-314. [CrossRef]

93. McMeekin, D.A.; West, G. Spatial Data Infrastructures and the Semantic Web of Spatial Things in Australia: Research Opportunities in SDI and the Semantic Web. In Proceedings of the 5th IEEE International Conference on Human System Interactions, Perth, Australia, 6-8 June 2012; pp. 197-201.

94. Zhang, C.; Zhao, T.; Li, W. Geospatial Semantic Web; Springer International Publishing: Cham, Switzerland, 2015; ISBN 978-3-319-17801-1.

95. Mirhaji, P. W3C: Semantic Web Use Cases and Case Studies. Case Study: Semantic Web Technology for Public Health Situation Awareness. Available online: https://www.w3.org/2001/sw/sweo/public/UseCases/ UniTexas/UT.pdf (accessed on 10 July 2017).

96. Feigenbaum, L.; Herman, I.; Hongsermeier, T. Scientific American. The Semantic Web in Action. Available online: https:/ / www.scientificamerican.com/article/semantic-web-in-actio/ (accessed on 8 July 2017).

97. Fa, J.S.H.; West, G.; McMeekin, D.A. Brokered Approach to Federating Data Using Semantic Web Techniques. In Proceedings of the Eighth International Conference on Advanced Geographic Information Systems, Applications, and Services (GEOProcessing 2016), Venice, Italy, 24-28 April 2016; pp. 46-55.

98. Yue, P.; Liping, D.; Wenli, Y. Semantics-based automatic composition of geospatial Web service chains. Comput. Geosci. 2007, 33, 649-665. [CrossRef]

99. MacEachren, A.M.; Kraak, M.J. Exploratory cartographic visualization: Advancing the agenda. Comput. Geosci. 1997, 23, 335-343. [CrossRef]

100. Veenendaal, B. Developing a map use model for web mapping and GIS. In Proceedings of the International Archives of the Photogrammetry, Remote Sensing and Spatial Information Sciences, Sardinia, Italy, 12-19 July 2015; pp. 31-34.

101. Cisco White Paper. The Zettabyte Era: Trends and Analysis. 2017. Available online: http:/ / www.cisco.com/c/en/us/solutions / collateral/service-provider/visual-networking-indexvni/vni-hyperconnectivity-wp.pdf (accessed on 8 July 2017).

102. Pappas, S. Live Science. How Big Is the Internet, Really? Available online: http:/ /www.livescience.com/ 54094-how-big-is-the-internet.html (accessed on 9 July 2017).

103. Whitehead, T. Google Erath Blog. How Big Is the Google Earth Database? Available online: http:/ / www. gearthblog.com/blog/archives/2016/04/big-google-earth-database.html (accessed on 12 July 2017).

104. Internet Live Statistics. Available online: http:/ / www.internetlivestats.com/ (accessed on 20 July 2017).

105. Li, S.; Dragicevic, S.; Castro, F.A. Geospatial big data handling theory and methods: A review and research challenges. ISPRS J. Photogramm. Remote Sens. 2016, 115, 119-133. [CrossRef]

106. ESA Sentinel Online. Available online: https://sentinel.esa.int/web/sentinel/sentinel-data-access (accessed on 7 July 2017).

107. Williams, A. Financial Times. Space-The Final Frontier for Investors. Available online: https://www.ft. com/content/05f24014-07e1-11e7-97d1-5e720a26771b?mhq5j=e1 (accessed on 13 July 2017).

108. Planet. Planet launches Satellite Constellation to Image the Whole Planet Daily. Available online: https:/ / www.planet.com/pulse/planet-launches-satellite-constellation-to-image-the-whole-planetdaily/ (accessed on 11 July 2017).

109. Planet. On-demand Webinar hosted by Descartes Labs on "Turning Geospatial Data into Intelligence". Available online: http: / info.planet.com/adp-webinar-1-on-demand/ (accessed on 11 July 2017).

110. Eckerson, W. Data Quality and the Bottom Line: Achieving Business Success through a Commitment to High Quality Data; Data Warehousing Institute: Seattle, WA, USA, 2002; Available online: http:/ / download.101com.com/ pub/tdwi/Files/DQReport.pdf (accessed on 8 July 2017). 
111. Mozilla. Using HTML Sections and Outlines. Available online: https:/ / developer.mozilla.org/en-US/docs / Web/Guide/HTML/Using_HTML_sections_and_outlines (accessed on 28 July 2017).

112. MapQuest Inc. MapQuest History. Available online: https://www.mindmeister.com/generic_files/get_file/ 446864\%3Ffiletype\%3Dattachment_file (accessed on 8 September 2016).

113. Privat, L. GPS Business News. Google Maps: 1 Billion Monthly Users. Available online: http://www. gpsbusinessnews.com/Google-Maps-1-Billion-Monthly-Users_a4964.html (accessed on 9 July 2017).

114. Seo, D.B.; Lee, J. Web 2.0 and five years since: How the combination of technological and organizational initiatives influences an organization's long-term Web 2.0 performance. Telemat. Inform. 2016, 33, 232-246. [CrossRef]

115. Google Maps Usage Statistics. Available online: https://trends.builtwith.com/mapping/Google-Maps (accessed on 8 July 2017).

116. SimilarTech. Google Maps: Websites Embedding Google Maps. Available online: https://www.similartech. com/technologies/google-maps (accessed on 11 July 2017).

117. Miller, C. A beast in the field: The Google Maps mashup as GIS/2. Cartographica 2006, 41, 187-199. [CrossRef]

118. Plantin, J.C. Participatory Mapping: New Data, New Cartography; Wiley-ISTE: London, UK, 2014; ISBN 978-1-84821-661-7.

119. GISCorps URISA. Welcome to GIS Corps! Available online: www.giscorps.org (accessed on 10 July 2017).

120. OpenStreetMap Stats Report Run. Available online: http://www.openstreetmap.org/stats/data_stats.html (accessed on 10 July 2017).

121. OSMstats. Available online: https:/ / osmstats.neis-one.org/?item=members (accessed on 8 July 2017).

122. Goodchild, M.F.; Li, L. Assuring the quality of volunteered geographic information. Spat. Stat. 2012, 1, 110-120. [CrossRef]

123. Wikimapia. 2017. Available online: http://wikimapia.org (accessed on 12 July 2017).

124. Steiniger, S.; Weibel, R. GIS Software-A description in 1000 words. In Encyclopedia of Geography; Warf, B., Ed.; SAGE Publications: Thousand Oaks, CA, USA, 2010; ISBN 9781412956970.

125. Foresman, T.W. Digital Earth visualization and web-interface capabilities utilizing 3D geobrowser technology. In Proceedings of the XXth International ISPRS Congress, Istanbul, Turkey, 12-23 July 2004; pp. 885-888.

126. Lake, R.; Farley, J. Infrastructure for the Geospatial Web. The Geospatial Web: How Geobrowsers, Social Software and the Web 2.0 are Shaping the Network Society. In Advanced Information and Knowledge Processing Series; Scharl, A., Tochtermann, K., Eds.; Springer: London, UK, 2007; ISBN 978-1-84628-827-2.

127. Hamerlinck, J.D. Naive (commonsense) geography and geobrowser usability after ten years of google earth. In Proceedings of the 9th Symposium of the International Society for Digital Earth (ISDE), Halifax, NS, Canada, 5-9 October 2015; pp. 12013-12020.

128. Trillium Learning. Earthquake Signal Precursors. Available online: http://aworldbridge.com/real-timeprojects / global-earthquake-forecasti (accessed on 12 July 2017).

129. Jun, Z.; Zhang, A.; Yin, L. 3D GIS modeling of Virtual High-Speed Railway Scene based on ArcGlobe. In Proceedings of the 7th International Conference on Image and Graphics, Qingdao, Shandong, China, 26-28 July 2013; pp. 811-815. [CrossRef]

130. Steiniger, S.; Hunter, A.J.S. The 2012 free and open source GIS software map-A guide to facilitate research, development, and adoption. Comput. Environ. Urban Syst. 2013, 39, 136-150. [CrossRef]

131. Kong, N.; Zhang, T.; Stonebraker, I. Evaluation of web GIS functionality in academic libraries. Appl. Geogr. 2015, 60, 288-293. [CrossRef]

132. Sun, Y.; Li, S. Real-time collaborative GIS: A technological review. ISPRS J. Photogramm. Remote Sens. 2016, 115, 143-152. [CrossRef]

133. ESRI. ArcGIS Online Help: What Is ArcGIS Online? Available online: http://doc.arcgis.com/en/arcgisonline/reference/what-is-agol.htm (accessed on 8 July 2017).

134. Environmental Systems Research Institute. ArcGIS Pro. 2017. Available online: http://pro.arcgis.com (accessed on 18 October 2017).

135. GFDRR. Open Data for Resilience Initiative \& GeoNode: A Case Study on Institutional Investments in Open Source. 2017. Available online: https:/ / opendri.org/wp-content/uploads/2017/03/OpenDRI_Investmentin-GeoNode_Report_March242017.pdf (accessed on 10 July 2017).

136. Boundless. GeoGig: Distributed Versioning of Geospatial Data. Available online: https://boundlessgeo. com/2014/03/geogit-distributed-versioning/ (accessed on 20 July 2017). 
137. Eom, K.; Arias, R.; Brovelli, M.A. UN Open GIS Initiative: the first year of activities. Geoengineer. Environ. Min. 2017. accepted for publication 25 September 2017.

138. Buytaert, W.; Baez, S.; Bustamante, M.; Dewulf, A. Web-based environmental simulation: Bridging the gap between scientific modeling and decision-making. Environ. Sci. Technol. 2012, 46, 1971-1976. [CrossRef] [PubMed]

139. Chaouchi, H. Chapter 1: Introduction to the Internet of Things. In The Internet of Things: Connecting Objects; Chaouchi, H., Ed.; John Wiley \& Sons, Inc.: Hoboken, NJ, USA, 2010; pp. 1-34. ISBN 978-1-84821-140-7.

140. Vitolo, C.; Elkhatib, Y.; Reusser, D. Web technologies for environmental Big Data. Environ. Model. Softw. 2015, 63, 185-198. [CrossRef]

141. Machina Research. IoT Global Forecast \& Analysis 2015-25. 2016. Available online: https:/ / machinaresearch. com/report/iot-global-forecast-analysis-2015-25 (accessed on 31 January 2017).

142. Davenport, T.H.; Patil, D.J. Data Scientist: The Sexiest Job of the 21st Century. Harv. Bus. Rev. 2012, 10, 70-76.

143. Li, S.; Veenendaal, B.; Dragićević, S. Advances, challenges and future directions in web-based GIS mapping services. In Advances in Web-Based GIS, Mapping Services and Applications; Li, S., Dragićević, S., Veenendaal, B., Eds.; Taylor \& Francis Group: London, UK, 2011; ISBN 978-0-415-80483.

144. Craglia, M.; de Bie, K.; Jackson, D. Digital Earth 2020: Towards the vision for the next decade. Int. J. Digit. Earth 2012, 5, 4-21. [CrossRef]

145. Zhang, J.; You, S.; Gruenwald, L. Towards GPU-Accelerated Web-GIS for Query-Driven Visual Exploration. In Proceedings of the 15th International Symposium on Web and Wireless Geographical Information Systems, Shanghai, China, 8-9 May 2017; pp. 119-136.

146. Han, G.; Chen, J.; He, C.; Li, S.; Wua, H.; Liao, A.; Peng, S. A web-based system for supporting global land cover data production. ISPRS J. Photogramm. Remote Sens. 2015, 103, 66-80. [CrossRef]

147. Duckham, M.; Arnold, L.; Armstrong, K.; McMeekin, D.; Mottolini, D. Towards a Spatial Knowledge Infrastructure; White Paper; Australia and New Zealand Cooperative Research Centre for Spatial Information (CRCSI): Melbourne, Australia, 2017.

148. Bouguettaya, A.; Singh, M.; Huhns, M. A service computing manifesto: The next 10 years. Commun. ACM 2017, 60, 64-72. [CrossRef] 